Journal for

ImmunoTherapy of Cancer

\section{Regulation of tumor growth by leukocyte-specific protein 1 in $T$ cells}

To cite: Kwon R, Hong B-K, Lee K-G, et al. Regulation of tumor growth by leukocytespecific protein 1 in T cells. Journal for ImmunoTherapy of Cancer 2020;8:e001180. doi:10.1136/jitc-2020-001180

- Additional material is published online only. To view, please visit the journal online (http://dx.doi.org/10.1136/jitc2020-001180).

Accepted 07 September 2020

Check for updates

(c) Author(s) (or their employer(s)) 2020. Re-use permitted under CC BY. Published by BMJ.

${ }^{1}$ Center for Integrative Rheumatoid Transcriptomics and Dynamics, The Catholic University of Korea, Seoul, Republic of Korea

${ }^{2}$ Department of Biomedicine \& Health Sciences, The Catholic University of Korea, Seoul,

Republic of Korea

${ }^{3}$ Department of Microbiology,

Infectiology, and Immunology, University of Montreal, Montreal, Quebec, Canada

${ }^{4}$ Division of Rheumatology, Department of Internal Medicine, The Catholic University of Korea, Seoul, Republic of Korea

\section{Correspondence to}

Professor Wan-Uk Kim; wan725@catholic.ac.kr

Dr Naeun Lee; nelee2015@catholic.ac.kr

\section{ABSTRACT}

Background Clinical efficacy of T cell-based cancer immunotherapy is limited by the lack of T cell infiltration in the tumor mass, especially in solid tumors. Our group demonstrated previously that leukocyte-specific protein 1 (LSP1), an intracellular signal regulator, negatively regulates $\mathrm{T}$ cell infiltration in inflamed tissues.

Methods To determine the immuno-regulatory effects of LSP1 in T cells on tumor progression, we investigated the growth of B16 melanoma in Lsp1 knockout (KO) mice and T cell-specific $L s p 1$ transgenic $(\mathrm{Tg})$ mice. The immune cell subpopulation infiltrated into the tumor mass as well as the expression of interferon-gamma (IFN- $\gamma$ ) and tumor necrosis factor-alpha (TNF- $\alpha$ ) in T cells was assessed by flow cytometry and/or immunohistochemistry. Chemotactic migration was assayed with $L s p 1 \mathrm{KO}$ and $L s p 1 \mathrm{Tg} \mathrm{T}$ cells. Adoptive transfer of $L s p 1 \mathrm{~K} 0$ or $L s p 1 \mathrm{Tg} T$ cells was performed in B16 melanoma-challenged Rag1 K0 mice. Results Lsp1 K0 mice showed decreased growth of B16 melanoma and increased infiltration of T cells in the tumor mass, which were completely reversed in T cellspecific $L s p 1 \mathrm{Tg}$ mice. $L s p 1 \mathrm{KO} C D 8^{+} \mathrm{T}$ cells also exhibited elevated migratory capacity in response to CXCL9 and CXCL10, whereas $L s p 1 \mathrm{Tg} \mathrm{CD8}^{+} \mathrm{T}$ cells did the opposite. LSP1 expression was increased in tumor-infiltrating T cells and could be induced by T cell receptor activation. Intriguingly, gene expression profiling of Lsp1 KO T cells suggested enhanced cytotoxicity. Indeed, expression of IFN- $\gamma$ and TNF- $\alpha$ was increased in tumor-infiltrating $\mathrm{CD}^{+}$ and $\mathrm{CD}^{+} \mathrm{T}$ cells of $L s p 1 \mathrm{KO}$ mice, while it was markedly reduced in those of $L s p 1 \mathrm{Tg}$ mice. Adoptive transfer of Lsp1 K0 T cells to Rag1 K0 mice was more effective in suppressing melanoma growth than transfer of $L s p 1 \mathrm{Tg}$ T cells. Of note, when treated with antiprogrammed cell death protein 1 (PD-1) antibody, inhibition of melanoma growth was more pronounced in $L s p 1 \mathrm{~K} 0$ mice than in Lsp1-sufficient mice, suggesting that $L s p 1$ depletion additively increases the antitumor effects of anti-PD-1 antibody.

Conclusions LSP1 in T cells regulates the growth of B16 melanoma in mice, possibly by affecting migration and infiltration of $\mathrm{T}$ cells into the tumor and by modulating production of antitumor effector cytokines by $\mathrm{CD}^{+} \mathrm{T}$ cells. These findings provide evidence that LSP1 can be a target to improve the efficacy of T cell-based immunotherapy.

\section{BACKGROUND}

Immune contexture, which consists of the density, composition and functional status of tumor-infiltrating leukocytes (TILs), determines tumor progression and the efficacy of antitumor immunotherapy, including antibody (Ab)-based immunotherapy against programmed cell death protein 1 (PD-1). ${ }^{1-3}$ Several studies have suggested that a high density of $\mathrm{T}$ cells positively correlates with favorable prognosis and survival in patients with various cancers, including colorectal, non-small cell lung, hepatocellular, pancreatic and gastric cancers and melanoma. ${ }^{12}$ Therefore, adoptive cell transfer using antigenactivated T cells, particularly chimeric antigen receptor (CAR)-T cells, has emerged as one of the promising strategies to improve the efficacy of anticancer therapy. ${ }^{4}$ For example, CD19-targeted CAR-T cell therapy has shown remarkably high rates of remission in patients with hematological malignancies, including relapsed or refractory B-cell acute lymphoblastic leukemia and lymphoma. ${ }^{45}$

Despite its success in hematological malignancies, CAR-T cell therapy is not always efficacious and has shown rather disappointing results in some patients with solid tumors. One of the major hurdles of $\mathrm{T}$ cell-based cancer immunotherapies is insufficient trafficking of $\mathrm{T}$ cells into tumor masses. ${ }^{4}$ Despite the infusion of large amounts of $\mathrm{T}$ cells after ex vivo expansion, only a small portion of transferred $T$ cells reaches inside the tumor tissues in clinical and preclinical studies. ${ }^{7}$ Although it remains unclear why trafficking, infiltration and penetration of $\mathrm{T}$ cells are insufficient, it may be primarily because solid tumors shape more fibrotic and less invasive environments through the activation of tumor-associated fibroblasts, ${ }^{8}$ ultimately constructing immunosuppressive tumor microenvironments (TME). Thus, to maximize the efficacy of $\mathrm{T}$ cell-based immunotherapy for solid tumors, it is essential to develop innovative ways for the successful delivery of immunocompetent $\mathrm{T}$ cells inside the tumor mass by destroying or detouring fibrotic and immunosuppressive TME. $^{89}$ 
Leukocyte-specific protein 1 (LSP1) is an intracellular F-actin-binding protein that is mainly expressed in hematopoietic cells, such as $\mathrm{T}$ and B lymphocytes, neutrophils and macrophages. ${ }^{10}$ Previous studies have reported a negative regulatory role of LSP1 in leukocyte recruitment to inflamed sites. ${ }^{10-12}$ After peritoneal injection of thioglycolate or intra-articular injection of zymosan, infiltration of macrophages and neutrophils was found to be higher in inflamed tissues of $L s p 1$ knockout (KO) mice than in those of wild-type (WT) mice. ${ }^{11}{ }^{12}$ Recently, our group also demonstrated that loss of Lsp1 promotes T cell migration into arthritic synovia and draining lymph nodes in mice with $\mathrm{T}$ cell-dependent chronic inflammation. ${ }^{13}$ Interestingly, several reports have suggested a possible link of LSP1 to the pathogenesis of various cancers, including breast cancer, ${ }^{14-16}$ bladder cancer, ${ }^{17}$ dermatofibroma ${ }^{18}$ and hepatocellular carcinoma ${ }^{19}{ }^{20}$ beyond its role in the migration of immune cells. For example, genetic variation in LSP1 has been implicated in susceptibility, prognostic outcomes and as a diagnostic marker in diverse types of cancers. ${ }^{14-19}{ }^{21}$ Moreover, a recent study showed that high LSP1 levels in glioblastoma serve as an independent predictive factor of unfavorable prognosis. ${ }^{22}$ However, it remains unclear whether LSP1 in T cells directly regulates tumor growth and how it contributes to the pathogenesis of cancers.

In this study, we postulated that Lsp1 deficiency promotes the antitumor activity of $\mathrm{T}$ cells by inducing cell migration and invasion into the tumor mass. We demonstrated that $L s p 1$ deficiency in T cells suppresses the growth of B16 melanoma in mice, which seems to be mediated by increased infiltration of $\mathrm{CD}^{+} \mathrm{T}$ cells into tumor sites and by enhanced production of interferongamma (IFN- $\gamma$ ) and tumor necrosis factor-alpha (TNF- $\alpha$ ), antitumor effector cytokines, by T cells. In contrast, $L s p 1$ overexpressing T cells show the opposite results. Notably, Lsp1 KO further potentiates the suppressive effect of antiPD-1 Ab on melanoma growth. Together, these results suggest that LSP1 depletion in T cells can be an effective strategy to overcome the current limitations of $\mathrm{T}$ cellbased immunotherapy and to improve the efficacy of antiPD-1 Ab for solid tumors.

\section{MATERIALS AND METHODS Animals}

Mice genetically deficient in the $L s p 1$ gene ( $L s p 1 \mathrm{KO}$ ) on the C57BL/ 6 background were kindly provided by Dr Laurent Sabbagh (University of Montreal, Montreal, Quebec, Canada) ${ }^{23}$ For the generation of $L s p 1$ transgenic (Lsp1 Tg) mice in which the $L s p 1$ gene was specifically overexpressed in T cells, mouse $L s p 1$ cDNA was cloned into a lymphocyte-specific expression cassette, including the human CD2 promoter. The construct was injected directly into the pronucleus of fertilized eggs and the transgenic founder was isolated by PCR of genomic DNA. To detect the Lsp1 transgene in Lsp1 Tg mice, genomic DNA was extracted from tails of WT and $L s p 1 \mathrm{Tg}$ mice, and then PCR analysis of the Lsp1 transgene was performed using the following primer sequences: forward, 5'-GGAC TCCACCAGTCTCACTTCAG-3' and reverse, 5'-CAGT TCAGAGGACTTCAGGCTGAT-3'. G protein signaling 7 gene (Rgs 7 ) was used as an internal control with the primers 5'-CAACCACTTACAAGAGACCCGTA-3' and 5'GAGCCCTTAGAAATAACGTTCACC-3'.

For the adoptive transfer experiments using $\mathrm{T}$ cells, Rag1 KO mice were obtained from Jackson Laboratory (Bar Harbor, Maine, USA). All strains were in the C57BL/ 6 background, and age-matched and sex-matched WT C57BL/ 6 mice were used as a control.

\section{Induction of B16 melanoma in mice}

The B16BL6 melanoma cell line (hereafter termed 'B16 melanoma') was purchased from the Korean Cell Line Bank (Seoul, Korea). The Lewis lung carcinoma (LLC) cell line was obtained from the American Type Culture Collection (Manassas, Virginia, USA). The MC38 colon adenocarcinoma cell line was kindly provided by Dr Tai-Gyu Kim (The Catholic University of Korea, Seoul, Korea). All cell lines were cultured in Dulbecco's Modified Eagle Medium (Welgene, Gyeongsan, Korea) supplemented with $10 \%$ heat-inactivated fetal bovine serum (FBS), $100 \mathrm{U} / \mathrm{mL}$ penicillin, $100 \mu \mathrm{g} / \mathrm{mL}$ streptomycin and $0.25 \mu \mathrm{g} / \mathrm{mL}$ Fungizone (Gibco; Thermo Fisher Scientific, Waltham, Massachusetts, USA). All cell lines used in this study were negative for Mycoplasma, when tested using an e-Myco Mycoplasma PCR Detection Kit (iNtRON Biotec, Seongnam, Korea). After being resuspended in phosphate buffered saline (PBS), $5 \times 10^{5} \mathrm{~B} 16$ melanoma cells, $1 \times 10^{5}$ MC38 cells or $2.5 \times 10^{5}$ LLC cells were injected subcutaneously into the right flank of mice aged 8-12 weeks. Tumor volumes were measured every 2-3 days with a caliper and calculated according to the following formula: $\mathrm{V}\left(\mathrm{mm}^{3}\right)=\mathrm{D} \times \mathrm{d}^{2} \times 0.52$, where $\mathrm{D}(\mathrm{mm})$ and $\mathrm{d}(\mathrm{mm})$ are the largest and smallest perpendicular tumor diameters, respectively.

\section{Isolation of TILs}

For isolation of TILs, the mice were sacrificed when the average WT tumor volume reached 500 or $700 \mathrm{~mm}^{3}$. After euthanizing mice, primary tumors were excised and dissociated by mechanical force. Tumor cell suspensions were obtained after filtration with a $70 \mu \mathrm{m}$ cell strainer. TILs were isolated using Ficoll-Hypaque (GE Healthcare, Chicago, Illinois, USA) density gradient centrifugation. The single-cell suspensions were washed in PBS and then subjected to flow cytometry analysis or in vitro re-stimulation for intracellular cytokine staining.

\section{Flow cytometry}

Single-cell suspensions were prepared from the tumor tissues and spleens of WT, Lsp1 KO and Lsp1 Tg mice after tumor inoculation. Surface staining was performed for $30 \mathrm{~min}$ at $4^{\circ} \mathrm{C}$ with the following fluorochrome-labeled antimouse Abs: CD45 (30-F11, BD Pharmingen, Franklin Lakes, New Jersey, USA), CD3 (145-2 C11, Invitrogen, 
Carlsbad, California, USA), CD4 (GK1.5, Biolegend, San Diego, California, USA), CD8 (53-6.7, Biolegend), CD19 (eBio 1D3, Invitrogen), NK1.1 (PK136, Biolegend), CD11b (M1/70, Biolegend), Ly-6C (HK1.4, Invitrogen), Ly-6G (1A8, Biolegend), F4/80 (BM8, Invitrogen), CD206 (C068C2, Biolegend), major histocompatibility complex (MHC) class II (M5/114.15.2, Biolegend) and CXCR3 (S18001A, Biolegend). To detect cytokine production, splenocytes and TILs were re-stimulated in vitro with phorbol-12-myristate-13-acetate $(50 \mathrm{ng} / \mathrm{mL}$, Sigma, St. Louis, MO) plus ionomycin (500 ng/mL, Sigma) for 4 hours in the presence of GolgiPlug (BD Bioscience). After surface staining, cells were fixed, permeabilized and stained with the following fluorochrome-labeled Abs: interleukin (IL)-2 (JES6-5H4, Biolegend), TNF- $\alpha$ (MP6XT22, Biolegend), IFN- $\gamma$ (XMG1.2, BD Biosciences) and Foxp3 (NRRF-30, Invitrogen) for 1 hour at $4^{\circ} \mathrm{C}$. Intracellular expression of LSP1 in T cells also was detected by flow cytometry. In brief, cells were stained with surface markers for $30 \mathrm{~min}$ at $4^{\circ} \mathrm{C}$. After surface staining, cells were fixed, permeabilized and incubated with rabbit anti-LSP1 Ab (Cell Signaling Technology, Danvers, Massachusetts, USA) or recombinant rabbit IgG (Abcam, Cambridge, UK) for 1 hour and then stained with a fluorescein isothiocyanate (FITC)-conjugated secondary Ab (Invitrogen) for $30 \mathrm{~min}$ to detect LSP1 expression in B16-challenged TILs, or they were stained with FITC-conjugated mouse anti-LSP1 Ab (mouse $\operatorname{IgG}_{1}$; BD Biosciences) for 1 hour to detect LSP1 expression in in vitro stimulated $\mathrm{T}$ cells.

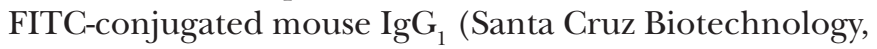
Dallas, Texas, USA) was used as an isotype control. Cells were resuspended in fluorescence-activated cell sorting (FACS) buffer and acquired through FACS Canto II (BD Biosciences) or LSR Fortessa (BD Biosciences) with DIVA software. All data were analyzed using FlowJo software (FlowJo, Franklin Lakes).

\section{Immunohistochemistry}

For immunohistochemical staining, $7 \mu \mathrm{m}$ sections of Optimal Cutting Temperature (OCT)-embedded tumor tissues were fixed with cold acetone for $10 \mathrm{~min}$ at $-20^{\circ} \mathrm{C}$, endogenous peroxidase was quenched by incubating the sections in $0.3 \% \mathrm{H}_{2} \mathrm{O}_{2}$ for $30 \mathrm{~min}$ at room temperature and then tissues were blocked with $10 \%$ normal donkey serum for 1 hour at room temperature. Tissue sections were incubated with rat antimouse CD4 (1:1000, Biolegend) or rat antimouse CD8 (1:1000, Biolegend) Ab overnight at $4^{\circ} \mathrm{C}$. Each slide was washed three times with PBS and detected using an antirat secondary Ab (1:100, Vector Laboratories, Burlingame, California, USA) with the VECTASTAIN Elite ABC HRP kit (Vector Laboratories). Positive cells were detected using 3,3'-diaminobenzidine tetrahydrochloride (Vector Laboratories) and counterstained with hematoxylin. Images were obtained using a Pannoramic MIDI slide scanner (3DHISTECH). Positive cells were counted manually in six fields per slide, with two different slides per mouse.

\section{Quantitative real-time PCR}

Total RNA was isolated from $\mathrm{T}$ cells of mouse spleen using the RNeasy Mini kit (Qiagen, Hilden, Germany), according to the manufacturer's instructions. For realtime quantitative PCR (qPCR), RNA was reverse transcribed to cDNA using RevertAid Reverse Transcriptase (Thermo Fisher Scientific), and qPCR was performed on the CFX96 real-time PCR system using SYBR Green PCR premix (Bio-Rad, Hercules, California, USA). The primer sequences used for detection of Lsp1 mRNA expression were 5'-CCAGCCCTTTGGCCTTAGAA-3' and 5'-TGGAAATGGGCAAGGTTGGT-3'. All samples were normalized to Gapdh expression detected using the primers 5'-AGGTCGGTGTGAACGGATTTG-3' and 5'TGTAGACCATGTAGTTGAGGTCA-3' and relative foldchange was calculated using the $2^{-\Delta \Delta \mathrm{Ct}}$ method.

\section{Western blot analysis of LSP1 and p-Akt}

Expression of LSP1 and phosphorylated Akt (p-Akt) in T cells was detected by western blot analysis. Briefly, stimulated $\mathrm{T}$ cells were lysed in a lysis buffer, and final protein concentrations were determined using a Bradford protein assay (Bio-Rad). Total protein was separated on 12\% SDS-PAGE gels and transferred to a polyvinylidene fluoride membrane by electroblotting. The membranes were incubated with Abs against LSP1 (1:1000), p-Akt (1:500), Akt (1:1000, all from Cell Signaling Technology) or $\beta$-tubulin (1:1000, Abcam), followed by horseradish peroxidase-conjugated antirabbit IgG (Thermo Fisher Scientific). The membranes were visualized using an enhanced chemiluminescent detection system (Thermo Fisher Scientific).

\section{T cell migration assay}

Chemotaxis of WT, Lsp1 KO and Lsp1 Tg CD8 ${ }^{+} \mathrm{T}$ cells was performed in 24-well plates with $5 \mu \mathrm{m}$ pore size Transwell inserts (Corning, Corning, New York, USA). Murine CXCL9 and CXCL10 (R\&D Systems, Minneapolis, Minnesota, USA) were diluted to the indicated concentrations in migration medium (0.1\% FBS in RPMI1640) and placed in the lower chamber. A half million $\mathrm{CD} 8^{+} \mathrm{T}$ cells were loaded into the upper chamber in migration medium. After 4 hours of incubation at $37^{\circ} \mathrm{C}$, the cells that had migrated to the lower chamber were counted using a hemocytometer. In some experiments, WT and Lsp1 KO CD4 ${ }^{+} \mathrm{T}$ cells were co-cultured with carboxyfluorescein succinimidyl ester (CFSE, $1 \mu \mathrm{M}$, Thermo Fisher Scientific)-labeled WT CD8 ${ }^{+} \mathrm{T}$ cells in the absence or presence of anti-CD3 Ab. After 3 days, cells were harvested and resuspended in migration medium and loaded in the upper chamber after CXCL9 or CXCL10 were added in the bottom chamber. After 4 hours of incubation, CFSElabeled $\mathrm{CD}^{+} \mathrm{T}$ cells that had migrated to the lower chamber were calculated by flow cytometry.

\section{T cell culture}

Splenic T cells of WT mice were cultured to examine the major stimuli and their signaling pathways to induce 
LSP1 expression. Briefly, T cells were isolated from the spleens and prepared as single-cell suspensions. $\mathrm{CD} 4^{+} \mathrm{T}$ cells or $\mathrm{CD} 8^{+} \mathrm{T}$ cells were purified by magnetic separation using anti-CD4 beads or anti-CD8 beads (Miltenyi Biotec, Bergisch Gladbach, Germany) according to the manufacturer's instructions. Purified $\mathrm{CD} 4^{+} \mathrm{T}$ cells or $\mathrm{CD} 8^{+} \mathrm{T}$ cells were stimulated with recombinant IFN- $\gamma(10 \mathrm{ng} /$ $\mathrm{mL}, \mathrm{R} \& \mathrm{D}$ Systems), transforming growth factor- $\beta$ (TGF- $\beta$, $2 \mathrm{ng} / \mathrm{mL}, \mathrm{R} \& D$ Systems), IL-10 (10 ng/mL, R\&D Systems) or antimouse CD $3 \varepsilon \mathrm{Ab}(1 \mu \mathrm{g} / \mathrm{mL}, 145-2 \mathrm{C} 11$, Invitrogen) plus antimouse CD28 Ab $(1 \mu \mathrm{g} / \mathrm{mL}, 37.51$, Invitrogen $)$ in complete media for 72 hours. In some experiments, ciclosporin A (Sigma), tacrolimus (FK506, Sigma) and rapamycin (Sigma) were treated to the $\mathrm{T}$ cells stimulated with anti-CD3/anti-CD28 Abs for 72 hours to determine whether the calcineurin pathway is involved in LSP1 expression. The cultured cells were harvested and stained to detect intracellular LSP1 expression by flow cytometry and/or western blot analysis.

\section{T cell proliferation and apoptosis assay}

$\mathrm{T}$ cell proliferation was assessed by flow cytometry analysis of CFSE-stained cells according to the manufacturer's instructions. Briefly, isolated $\mathrm{CD}^{+}$or $\mathrm{CD}^{+} \mathrm{T}$ cells were resuspended in PBS at a density of $1 \times 10^{7}$ cells/ $\mathrm{mL}$ and incubated with $1 \mu \mathrm{M}$ of CFSE (Invitrogen) for $10 \mathrm{~min}$ at room temperature in the dark. Stained cells were quenched using FBS for $10 \mathrm{~min}$ on ice. The cells were washed twice and resuspended in complete RPMI 1640 medium and then analyzed by flow cytometry. Apoptosis was measured using the FITC-Annexin V Apoptosis Detection Kit (BD Bioscience) according to the manufacturer's protocol. In brief, cultured T cells were harvested, washed with PBS and resuspended in annexin V-binding buffer. The cells were gently mixed with FITC-annexin V and propidium iodide (PI) and then incubated for $15 \mathrm{~min}$ at room temperature in the dark. Subsequently, annexin $\mathrm{V}^{+}$and/or $\mathrm{PI}^{+}$cells were analyzed by flow cytometry.

\section{Microarray and gene set enrichment analysis}

Total RNA was isolated from splenic T cells of $L s p 1 \mathrm{KO}$ and WT mice, which were stimulated with anti-CD3/antiCD28 Abs for 6 hours. The RNA was reverse-transcribed, amplified according to standard Agilent protocols, and then hybridized to an array chip (SurePrint G3 Mouse GE $8 \times 60 \mathrm{~K}$ Microarray, Agilent) containing 62976 probes for 24241 annotated genes (GSE75123). Briefly, after normalization, the log2 fold-change values and $p$ values of each gene were calculated as previously described. ${ }^{13}$ The cut-off values of differentially expressed genes (DEGs) in Lsp1 KO T cells were as follows: |fold-change valuesl > Ithe fold-change values of 2.5th and 97.5th percentile of the empirical null distributionl and $p$ values $<0.05$. Functional enrichment analysis of DEGs was performed using DAVID Bioinformatics Resources 6.8 (https://david. ncifcrf.gov/). The GOBP terms of leukocyte related were first selected based on their titles and definitions. Gene set enrichment analysis (GSEA) was performed by clusterProfiler (R package, V.3.4.6) ${ }^{24}$ and GSEA plots were generated with enrichrplot ( $\mathrm{R}$ package).

\section{Adoptive transfer of T cells to Rag1 KO mice}

Rag1 KO mice were inoculated subcutaneously with $1 \times 10^{5}$ B16 melanoma cells in the right flank. Next day, T cells were isolated from spleens of non-tumor-bearing Lsp1 $\mathrm{KO}$ and Lsp1 Tg mice by magnetic separation using a Pan $\mathrm{T}$ cell isolation kit (Miltenyi Biotec) according to the manufacturer's instructions. PBS as a vehicle or $1 \times 10^{7} \mathrm{~T}$ cells from $L s p 1 \mathrm{KO}$ or $L s p 1 \mathrm{Tg}$ mice were injected intravenously into B16 melanoma-bearing Rag1 KO mice. Tumor growth was recorded every other day.

\section{Combination immunotherapy with anti-PD-1 blockade}

For anti-PD-1 blockade therapy, $5 \times 10^{5}$ B16 melanoma cells were inoculated subcutaneously into the right flank of WT and Lsp1 KO mice. On days 3, 6, 9 and 12 after tumor inoculation, the tumor-bearing mice were treated intraperitoneally with $10 \mathrm{mg} / \mathrm{kg}$ anti-PD-1 Ab (RMP1-14, Bio X cell, Lebanon, New Hampshire, USA) or matched rat IgG2a isotype control (2A3, Bio X cell). Tumor growth was monitored every other day.

\section{Statistical analysis}

Statistical analysis was conducted using GraphPad Prism software. The unpaired t-test was used for statistical evaluations as indicated in each experiment, while two-way analysis of variance analysis was performed to determine the significance of tumor growth. Data are shown as the mean \pm SD. $\mathrm{P}$ values $<0.05$ were considered to be statistically significant.

\section{RESULTS}

LSP1 deficiency restrains tumor growth while promoting T cell infiltration in tumors

The role of LSP1 for tumor immunity remains to be defined. To address this issue, we subcutaneously inoculated syngeneic B16 melanoma cells into WT and Lsp1 $\mathrm{KO}$ mice and then observed tumor growth over 3 weeks. We found that Lsp1 KO mice had significant reductions in tumor growth as compared with WT mice (figure 1A). Moreover, tumor volume and weight in Lsp1 KO mice were lower than in WT mice as determined on day 14 after tumor inoculation (figure 1B,C). To explore whether the inhibitory effect of Lsp1 deficiency on tumor growth is reproduced in other types of solid tumor, we assessed the growth of MC38 colon cancer in WT and Lsp1 KO mice. Similar to the results obtained in the B16 melanoma model, the growth of MC38 colon cancer cells was significantly diminished in $L s p 1 \mathrm{KO}$ mice (online supplemental figure 1A). However, there was no difference in the growth of LLC between WT and Lsp1 KO mice (online supplemental figure 1B).

To characterize the effects of Lsp1 deficiency on immune contexture in the TME, TILs in tumor-bearing WT and Lsp1 KO mice were first analyzed using flow 
A

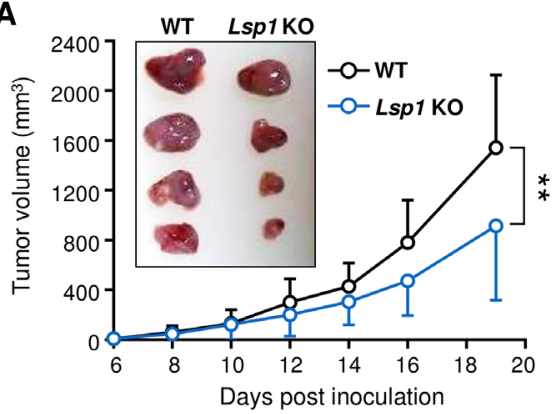

D

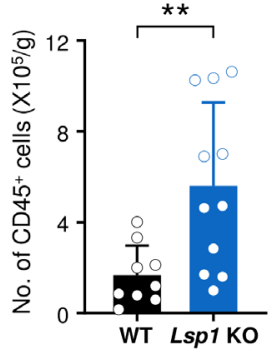

E

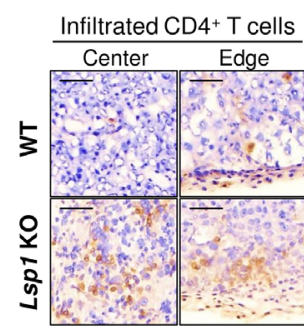

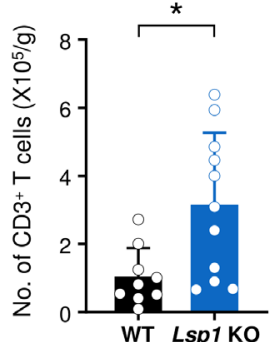

WT Lsp1 KO
B
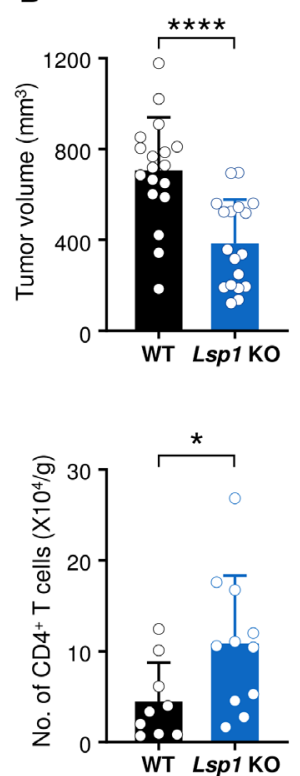

C
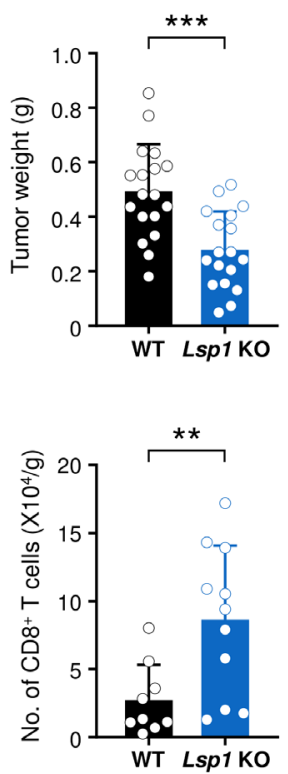

F

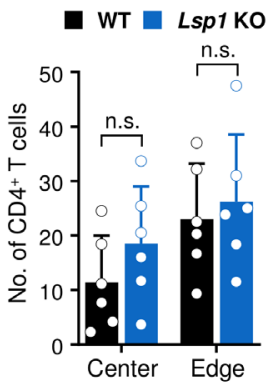

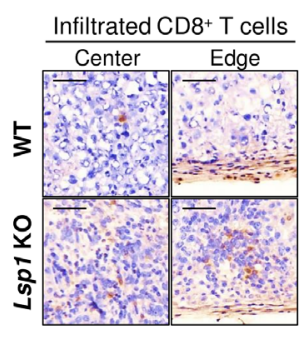

WT $\square$ Lsp1 KO

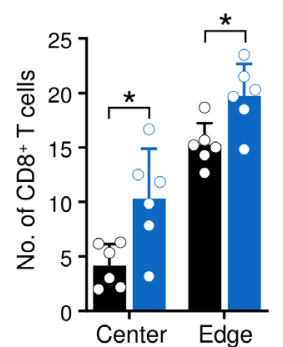

G
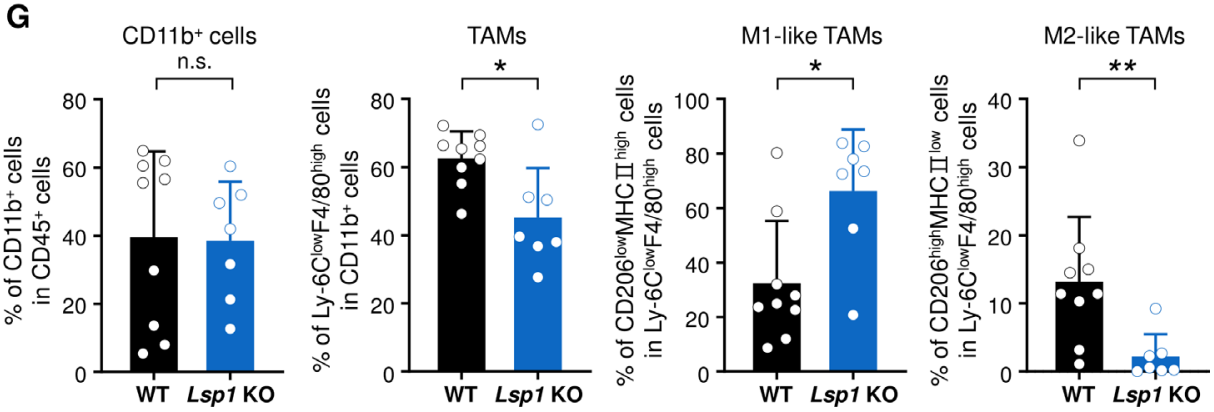

Figure 1 Effect of leukocyte-specific protein 1 (Lsp1) deficiency on melanoma growth and T cell infiltration in tumors. (A) Tumor growth in wild-type (WT) $(n=11)$ and $L s p 1$ knockout $(K O)$ mice $(n=9)$. Mice were subcutaneously injected with $B 16$ melanoma cells and tumor growth was measured at the indicated time points. (B and C) Tumor volume and weight in WT and Lsp1 KO mice ( $\mathrm{n}=18$ per group). When the average volume of tumors in WT mice reached approximately $700 \mathrm{~mm}^{3}$, tumor weight was assessed in the two groups of mice. (D) The number (No.) of tumor-infiltrating leukocytes (TILs), in tumors from B16 melanoma-challenged WT $(n=9)$ and $L s p 1$ KO mice $(n=11)$, which was assessed by flow cytometry at the same time, as described in (B and $\mathrm{C})$. The gating strategy for flow cytometry analysis is shown in online supplemental figure 2A. (E and $F)$ Immunohistochemical staining of $\mathrm{CD}^{+}$or $\mathrm{CD}^{+} \mathrm{T}$ cells in frozen sections of melanoma obtained from WT and $L s p 1 \mathrm{KO}(\mathrm{n}=3$ per group) mice. Representative images of $\mathrm{CD} 4^{+} \mathrm{T}$ cells ( $\mathrm{E}$, left panel) and $\mathrm{CD} 8^{+} \mathrm{T}$ cells ( $\mathrm{F}$, left panel) infiltrated into the center or edge of the tumor are shown in brown. The sections were counterstained with hematoxylin. Scale bar indicates $50 \mu \mathrm{m}$ for all images. The mean number of infiltrating $\mathrm{CD}^{+}\left(\mathrm{E}\right.$, right panel) or $\mathrm{CD}^{+}$(F, right panel) $\mathrm{T}$ cells was calculated from two slides per tumor tissue and five to six fields per slide. (G) Comparison of the frequencies of CD11 $\mathrm{b}^{+}$cells in $\mathrm{CD}_{4} 5^{+}$leukocytes, Ly-6C $C^{\text {low }} F 4 / 80^{\text {high }}$ cells (tumor-associated macrophages (TAMs)) in CD11 b ${ }^{+}$cells, and CD206 ${ }^{\text {low }} M H C{ }^{\text {high }}$ (M1-like TAMs) or $\mathrm{CD}^{206} 6^{\text {high }} \mathrm{MHCII}^{\text {low }}$ cells (M2-like TAMs) in Ly-6C ${ }^{\text {low }} \mathrm{F} 4 / 80^{\text {high }}$ cells between WT $(\mathrm{n}=9)$ and Lsp1 KO mice $(\mathrm{n}=7)$. Representative zebra plots and the gating strategy for flow cytometry analysis are presented in online supplemental figure 2D. Data are the mean $\pm S D$ of at least two independent experiments. The circle in the bar graphs represents the individual value. $P$ values were determined by two-way analysis of variance analysis $(A)$ or unpaired two-tailed t-test $(B-G)$. n.s., not significant. ${ }^{*} P<0.05$; ${ }^{* *} \mathrm{p}<0.01 ;{ }^{* * *} \mathrm{p}<0.001 ;{ }^{* * \star *} \mathrm{p}<0.0001$. 
cytometry when the average tumor volume in WT mice reached approximately $700 \mathrm{~mm}^{3}$. The results showed that tumors derived from $L s p 1 \mathrm{KO}$ mice had a greater number of infiltrated $\mathrm{CD} 45^{+}, \mathrm{CD}^{+}, \mathrm{CD} 4^{+}$and $\mathrm{CD}^{+} \mathrm{T}$ cells than those from WT mice (figure 1D) and that the frequencies of those cells were not different between WT and $L s p 1 \mathrm{KO}$ mice (online supplemental figure 2A,B). These results imply that reduced melanoma growth in $L s p 1 \mathrm{KO}$ mice may be related to the increased numbers of $\mathrm{T}$ cells rather than composition. A growing body of evidence suggests that the spatial distribution of TILs, specifically whether the cells are located at the center or invasive margin of a tumor, as well as immune heterogeneity of TILs, critically determines the responsiveness to antitumor immunotherapy. ${ }^{12526}$ In this melanoma model, infiltration of $\mathrm{CD} 8^{+} \mathrm{T}$ cells, but not that of $\mathrm{CD} 4^{+} \mathrm{T}$ cells, was significantly higher in both the center and edge regions of the tumors in Lsp1-deficient mice than in WT mice, as assessed by immunohistochemical staining (figure 1E,F), indicating that $L s p 1$ deficiency promotes $\mathrm{CD} 8^{+} \mathrm{T}$ cell infiltration into the tumor center.

In addition to $\mathrm{T}$ cells, other immune cell populations contribute to the TME. We found that there were no differences in the frequencies of intratumoral NK1.1 $1^{+}$ natural killer (NK) cells and $\mathrm{CD}^{+} 9^{+} \mathrm{B}$ cells (online supplemental figure 2C), even though the absolute numbers of TILs were higher in the tumors derived from Lsp1 KO mice. The frequency of regulatory $\mathrm{T}$ cells $\left(\mathrm{T}_{\text {reg }}\right.$ cells: Foxp $3^{+} \mathrm{CD} 4^{+} \mathrm{T}$ cells), a representative subset of immunosuppressors in the tumor milieu, also showed no difference (online supplemental figure 2C). Among TILs, the myeloid cell population is another substantial component of the TME that regulates tumor growth. ${ }^{18}$ Interestingly, the frequency of CD $11 b^{+}$Ly6C $\mathrm{C}^{\text {low- }}$ $\mathrm{F} 4 / 80^{\text {high }}$ tumor-associated macrophages (TAMs) was also significantly decreased in the tumors of $L s p 1 \mathrm{KO}$ mice compared with those of WT mice, although the frequency of $\mathrm{CD}_{11 \mathrm{~b}^{+}}$myeloid cells was similar between $L s p 1 \mathrm{KO}$ and WT mice (online supplemental figure 2D and figure 1G). Of note, among TAMs, there was a significant increase of pro-inflammatory M1-like (CD206 ${ }^{\text {low }}$ MHCII $^{\text {high }}$ ) TAMs and a substantial decrease of anti-inflammatory M2-like (CD206 ${ }^{\text {high }}$ MHCII ${ }^{\text {low }}$ ) TAMs in the tumors of Lsp1 KO mice (online supplemental figure 2D and figure $1 \mathrm{G}$ ).

Collectively, these results demonstrate that Lsp1deficient mice establish a more favorable antitumor immune milieu by enhancing infiltration of pro-inflammatory M1-like rather than M2-like TAMs as well as that of $\mathrm{CD} 8^{+} \mathrm{T}$ cells.

\section{LSP1 overexpression in T cells promotes melanoma growth while suppressing $\mathrm{T}$ cell infiltration in tumors}

To extend our understanding of the T cell-specific effects of LSP1 during tumor development, we generated transgenic $(\mathrm{Tg})$ mice that specifically overexpress $L s p 1$ in $\mathrm{T}$ cells using CD2 promoter, as described in 'Materials and methods' section (figure 2A). We first confirmed that $\mathrm{CD} 4^{+}$ and $\mathrm{CD}^{+} \mathrm{T}$ cells in $L s p 1 \mathrm{Tg}$ mice expressed much higher levels of $L s p 1$ mRNA than those in WT mice (figure 2B,C). WT and Lsp1 Tg mice were subcutaneously challenged with B16 melanoma cells, as shown in figure 1. In sharp contrast with $L s p 1 \mathrm{KO}$ mice, $L s p 1 \mathrm{Tg}$ mice showed substantial acceleration of tumor growth over a period of 3 weeks in comparison to WT mice (figure 2D). At day 14 after tumor inoculation, the volume and weight of the tumors derived from $L s p 1 \mathrm{Tg}$ mice were also significantly higher than those of WT mice (figure 2E,F).

Since CD2 promoter drives early expression of the transgene in the double negative stage of thymocytes, it is conceivable that high LSP1 expression in $\mathrm{CD}_{2}^{+} \mathrm{T}$ cells would affect $\mathrm{T}$ cell development in the thymus. Here, we found no differences in the number of total thymocytes and the frequencies of cells in thymus developmental stages from double negative cells to single positive cells between WT and Lsp1 Tg mice, as determined by flow cytometry (online supplemental figure 3A). Additionally, no differences were observed in the peripheral $\mathrm{T}$ cell numbers and the ratio of $\mathrm{CD}^{+}$or $\mathrm{CD} 8^{+} \mathrm{T}$ cell population in blood and spleens of WT versus Lsp1 Tg mice (online supplemental figure 3B,C). Together, these data suggest that CD2-driven Lsp1 overexpression does not affect $T$ cell education and homeostasis. In support of this notion, it has been demonstrated that Lsp1 deficiency does not affect $\mathrm{T}$ cell development and homeostasis in the central and peripheral tissues. ${ }^{11}$

To evaluate the immune cell population in the TME of Lsp1 Tg mice, tumors were collected when tumor volume derived from WT mice reached approximately $500 \mathrm{~mm}^{3}$ and then the number and frequency of TILs were analyzed using flow cytometry (figure 2G). The results showed that the frequencies of tumor-infiltrating $\mathrm{CD}^{+}$and $\mathrm{CD}^{+} \mathrm{T}$ cells were similar between $\mathrm{WT}$ and $L s p 1$ $\mathrm{Tg}$ mice. However, in contrast to the results in $L s p 1 \mathrm{KO}$ mice, the frequency of $\mathrm{CD}^{+} \mathrm{T}$ cells was reduced in $L s p 1$ $\mathrm{Tg}$ as compared with WT mice (figure $2 \mathrm{G}$ ). The absolute number of intratumoral $\mathrm{CD} 45^{+}, \mathrm{CD}^{+}$and, especially, $\mathrm{CD}^{+} \mathrm{T}$ cells was also significantly lower in $L s p 1 \mathrm{Tg}$ mice than in WT mice (figure $2 \mathrm{H}$ ). As expected, since $L s p 1$ overexpression is specific to T cells, no difference was found in the frequency of intratumoral NK1.1 $1^{+} \mathrm{NK}$ cells, CD19 $\mathrm{B}$ cells, $\mathrm{CD} 11 \mathrm{~b}^{+}$myeloid cells and even TAMs between the two types of mice (online supplemental figure 4). Collectively, these results show that specific overexpression of Lsp1 in T cells enhances B16 melanoma growth, which is associated with a decrease in the number and frequency of TILs, particularly CD8 ${ }^{+} \mathrm{T}$ cells.

The decreased infiltration of $L s p 1 \mathrm{Tg} \mathrm{CD}^{+} \mathrm{T}$ cells could be due to the reduction of $\mathrm{T}$ cell survival and proliferation. To test this possibility, we checked the proliferation and survival of B16-challenged Lsp1 Tg versus WT $\mathrm{T}$ cells in the presence or absence of anti-CD3/ anti-CD28 Abs using flow cytometry. As shown in online supplemental figure 5, no differences were found in the frequencies of CFSE-diluted cells or annexin $\mathrm{V}^{+}$and/or $\mathrm{PI}^{+}$cells in $\mathrm{CD}^{+}$and $\mathrm{CD} 8^{+} \mathrm{T}$ cells between the two groups of mice, suggesting that other mechanism(s) than cell 
A

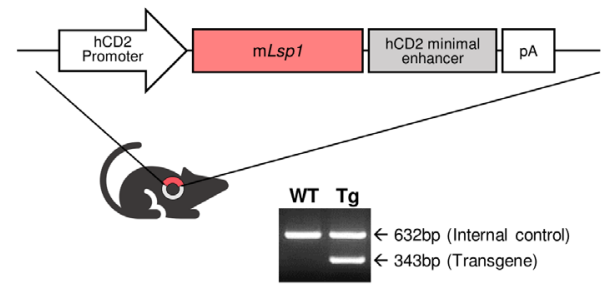

D

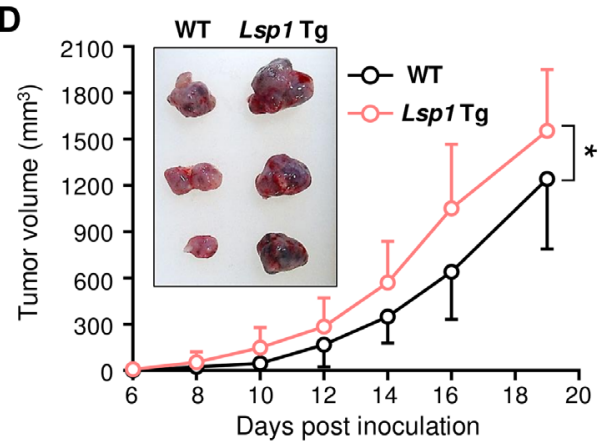

B

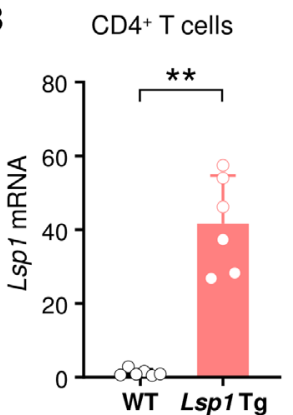

E

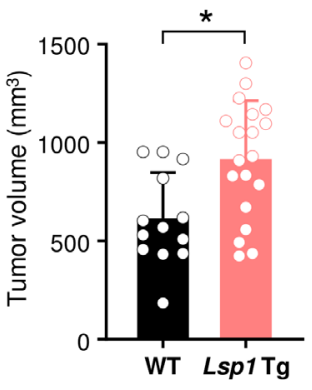

C $\quad \mathrm{CD}^{+} \mathrm{T}$ cells

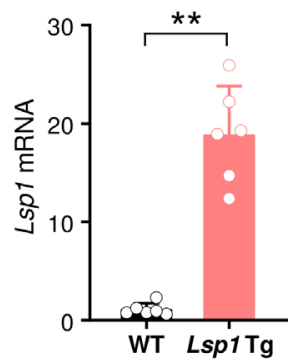

$\mathbf{F}$

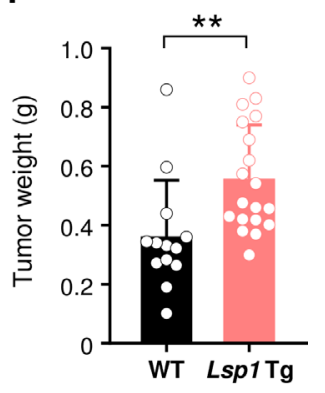

G

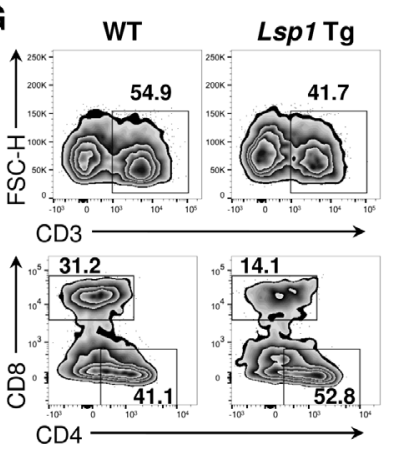

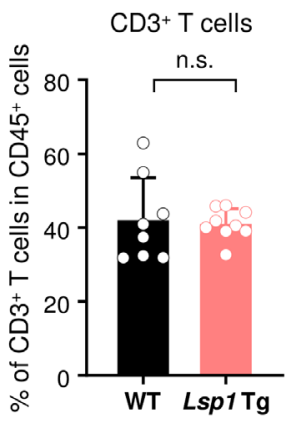

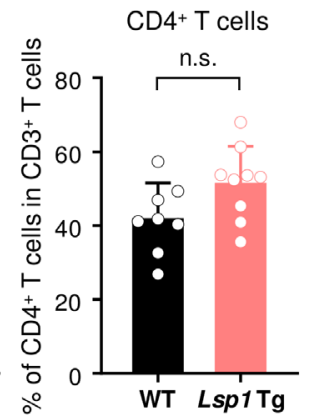

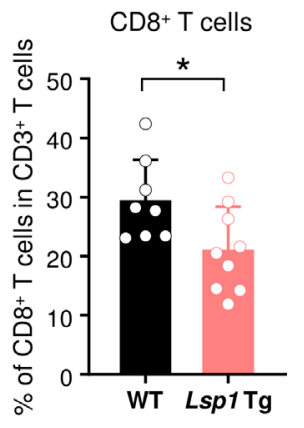
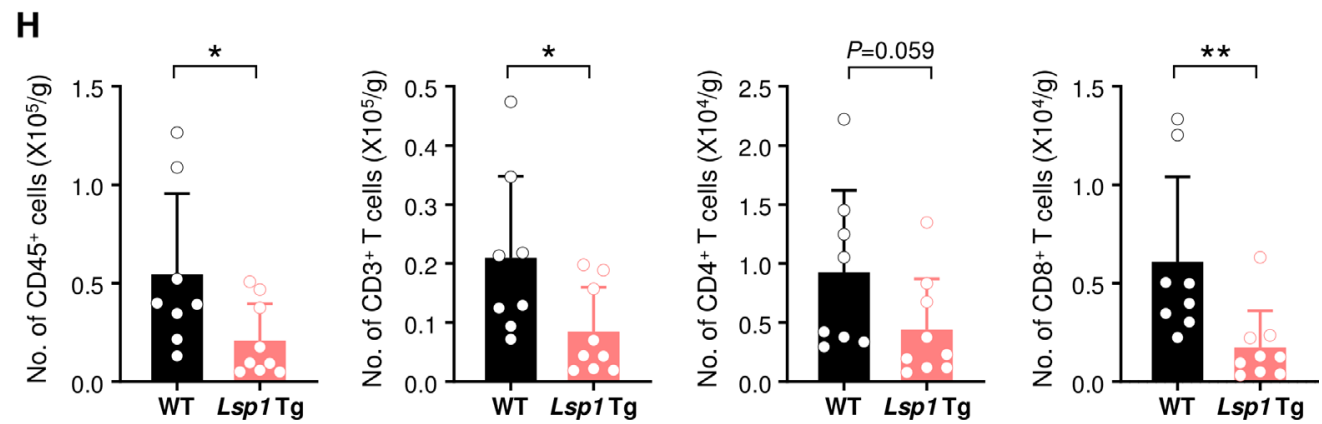

Figure 2 Increase in growth of melanoma and decrease in infiltration of T cells by T cell-specific leukocyte-specific protein 1 (Lsp1) overexpression. (A) Generation of T cell-specific Lsp1-overexpressing mice. Diagram shows the structure of the $L s p 1$ transgenic ( $\mathrm{Tg}$ ) construct containing a hCD2 promoter-Lsp1 transgene (top panel). PCR analysis of the Lsp1 transgene and an internal control gene (G protein signaling 7; Rgs7) was performed with genomic DNA isolated from wild-type (WT) and Lsp1 Tg mice (bottom panel). (B and C) Quantitative real-time PCR analysis of $L s p 1$ mRNA expression levels in splenic CD4 ${ }^{+} T$ cells and $\mathrm{CD}^{+} \mathrm{T}$ cells of WT and $L s p 1 \mathrm{Tg}$ mice ( $\mathrm{n}=6$ per group). Gapdh was used as an internal control. Fold inductions were calculated using the $2^{-\Delta \Delta C t}$ method. (D) Tumor growth in WT $(n=12)$ and $L s p 1$ Tg mice $(n=11)$. Mice were subcutaneously injected with $B 16$ melanoma cells and tumor growth was measured at the indicated time points. ( $E$ and F) Tumor volume and weight in WT $(n=13)$ and Lsp1 Tg mice $(n=19)$. When the average volume of tumors in WT mice reached approximately $500 \mathrm{~mm}^{3}$, tumor weight was assessed in the two groups of mice. $(G$ and $H)$ Flow cytometry analysis of T cells infiltrated in B16 melanoma. The cells were isolated from the tumors of WT $(n=8)$ and $L s p 1 \operatorname{Tg}$ mice $(n=9)$ at the same time as described in ( $E$ and $F)$. The frequencies of $\mathrm{CD}^{+} \mathrm{T}$ cells in $\mathrm{CD} 45^{+}$leukocytes and those of $\mathrm{CD}^{+}$or $\mathrm{CD}^{+} \mathrm{T}$ cells in $\mathrm{CD}^{+} \mathrm{T}$ cells are shown in (G) as representative zebra plots and bar graphs. The number (No.) of T cells is presented in $(\mathrm{H})$. Data are the mean \pm SD of at least two independent experiments. The circle in the bar graphs indicates the individual value. $P$ values were determined by two-way analysis of variance analysis $(D)$ or unpaired two-tailed t-test $(B, C$ and $E-H)$. n.s., not significant. ${ }^{*} P<0.05 ;{ }^{* \star} p<0.01$. 
proliferation and survival are responsible for the decrease of TILs in the melanoma of Lsp1 Tg mice.

\section{LSP1 negatively regulates $\mathrm{CD8}^{+} \mathrm{T}$ cell migration}

Previously, we demonstrated that $L s p 1$ deficiency directly increases $\mathrm{CD}^{+} \mathrm{T}$ cell migration in response to stromal cell-derived factor-1, a major chemokine that is known to be involved in $\mathrm{CD} 4^{+} \mathrm{T}$ cell migration under arthritisassociated conditions. ${ }^{13}$ In this study, we tested whether LSP1 affects $\mathrm{CD} 8^{+} \mathrm{T}$ cell migration under tumor-associated conditions. It is widely accepted that the CXCR3-CXCL9/ CXCL10 axis has a crucial role in driving the trafficking of $\mathrm{CD}^{+} \mathrm{T}$ cells to tumor sites. ${ }^{27}$ Moreover, activation of that axis promotes the interaction between tumor-specific $\mathrm{T}$ cells and dendritic cells in the TME during anti-PD-1 therapy. ${ }^{28}$ We, therefore, investigated whether LSP1 controls $\mathrm{CD}^{+} \mathrm{T}$ cell migration in response to CXCL9 and CXCL10. We found that Lsp1-deficient $\mathrm{CD}^{+} \mathrm{T}$ cells showed a greater chemotactic response to CXCL9 and CXCL10 than WT CD8 ${ }^{+}$T cells (figure 3A). By contrast, Lsp1-overexpressing $\mathrm{CD}^{+} \mathrm{T}$ cells displayed diminished chemotactic migration compared with $\mathrm{WT}$ and Lsp1deficient $\mathrm{CD}^{+} \mathrm{T}$ cells (figure $3 \mathrm{~A}$ ), demonstrating that LSP1 negatively regulates the migration of $\mathrm{CD}^{+} \mathrm{T}$ cells. However, migration of $\mathrm{CD}^{+} \mathrm{T}$ cells stimulated with $10 \%$ FBS did not differ among the three types of $\mathrm{CD}^{+} \mathrm{T}$ cells (figure 3A), suggesting that LSP1 regulation of $\mathrm{CD}^{+} \mathrm{T}$ cell migration is specific to CXCL9 and CXCL10.

To mechanistically understand how $\mathrm{T}$ cell migration is modulated by LSP1 expression, we first examined the expression level of CXCR3, a specific receptor of CXCL9 and CXCL10, on T cells of WT, Lsp1 KO and Lsp1 Tg mice. As shown in online supplemental figure $6 \mathrm{~A}$ and $\mathrm{B}$, no differences in CXCR3 expression levels were observed among the three genotypes. Additionally, our microarray data showed that there was a paucity of chemokine receptor-related genes in the DEGs (online supplemental figure 6C), implying that expression of chemokine receptors, particularly with CXCR3, is not relevant to LSP1 control of T cell migration. Earlier studies demonstrated that CXCL9/10-CXCR3 axis transmits its signals through the Akt. ${ }^{29}$ Therefore, we next investigated to determine if Akt is a downstream target of LSP1 for T cell migration. As shown in figure $3 \mathrm{~B}$, the expression level of p-Akt was reduced in Lspl $\mathrm{Tg} \mathrm{CD}^{+} \mathrm{T}$ cells on CXCL10 stimulation, as determined by western blot analysis. Conversely, CXCL10-triggered-p-Akt expression was higher in $\mathrm{CD}^{+} \mathrm{T}$ cells of Lsp1 KO mice than in those of WT mice (figure 3B), indicating that LSP1 is a negative regulator of Akt activation. CXCL9-stimulated Lsp1 $\mathrm{Tg} \mathrm{CD}^{+} \mathrm{T}$ cells showed similar results (data not shown). Moreover, the CXCL9/10-induced increase in $\mathrm{CD}^{+} \mathrm{T}$ cell migration was almost completely abrogated by the Akt inhibitor LY294002, but not by the Erk inhibitor PD98059 or p38 inhibitor SB203580 (figure 3C). Overall, these results suggest that LSP1 inhibits CXCL9/10induced $\mathrm{T}$ cell migration by regulating the extent of Akt phosphorylation.
To further demonstrate the pathological relevance of LSP1 in T cells to tumor conditions, we investigated LSP1 expression levels in TILs of B16 melanoma by flow cytometry. Specificity of the anti-LSP1 Ab was validated, as shown in figure $3 \mathrm{D}$. As shown in figure $3 \mathrm{E}, \mathrm{CD} 4^{+} \mathrm{T}$ cells infiltrated into B16 melanoma tissue, but not splenic $\mathrm{CD}^{+} \mathrm{T}$ cells in the same mice, exhibited substantially higher LSP1 expression than splenic T cells of nontumor-bearing mice. $\mathrm{CD}^{+} \mathrm{T}$ cells infiltrated into B16 melanoma tissue showed similar results, demonstrating that high levels of LSP1 in T cells are possibly induced by B16 melanoma. To better understand how the upregulation of LSP1 expression occurs in tumor-infiltrating $\mathrm{T}$ cells in vivo, we investigated which kinds of tumorassociated stimuli can induce LSP1 expression. As shown in figure $3 \mathrm{~F}$, stimulation of $\mathrm{T}$ cells with anti-CD3/antiCD28 Abs or IFN- $\gamma$, which is known as a pro-inflammatory cytokine abundantly produced in the TME, ${ }^{30}$ strongly increased LSP1 expression in both $\mathrm{CD}^{+}$and $\mathrm{CD}^{+} \mathrm{T}$ cells. The increase in LSP1 expression by T cell receptor (TCR) activation and IFN- $\gamma$ was confirmed by western blot analysis (figure 3G). By contrast, TGF- $\beta$ and IL-10, antiinflammatory cytokines derived from the TME, ${ }^{831}$ failed to upregulate LSP1 expression (figure 3F,G). Ciclosporin A and tacrolimus (FK506), specific calcineurin inhibitors, markedly suppressed anti-CD3/anti-CD28 Abs-induced increase in LSP1 expression, while rapamycin failed to do so, indicating that LSP1 induction by TCR activation is calcineurin-dependent (figure 3H). Given that LSP1 in $\mathrm{T}$ cells negatively regulates $\mathrm{T}$ cell migration, these results suggest that B16 melanoma can evade the antitumor activity of host T cells by upregulating LSP1 expression in $\mathrm{T}$ cells within the TME.

\section{Lsp1-deficient T cells show increased cytotoxicity}

We next questioned whether LSP1 regulation of tumor growth originates entirely from its effect on $\mathrm{T}$ cell migration. To answer this question, we unbiasedly analyzed the global transcriptome profile of Lsp1 KO T cells (GSE75123), which was generated by our group in a previous study. ${ }^{13}$ As compared with WT T cells, 1256 DEGs (721 upregulated and 535 downregulated DEGs) were identified in Lsp1 KO T cells under media or antiCD3/anti-CD28 Abs stimulated conditions (figure 4A). We next tried to define the major cellular processes represented by the DEG (online supplemental table 1; all supplemental tables are available at https://www.ciradcatholic.com/supplementary-figures-data). Functional enrichment analysis demonstrated that the immune system process, response to stimulus, cell adhesion, localization, developmental process, cell signaling and cell killing were significantly enriched $(\mathrm{p}<0.01)$ by the DEGs in Lsp1 KO T cells (figure 4B and online supplemental table 2). Among the 17 parent GOBP terms in figure 4B, we further analyzed the child GOBP terms related to leukocyte biology and then calculated their enrichment scores. As a result, 'leukocyte-mediated migration' and 'leukocyte-mediated cytotoxicity' were significantly 
A

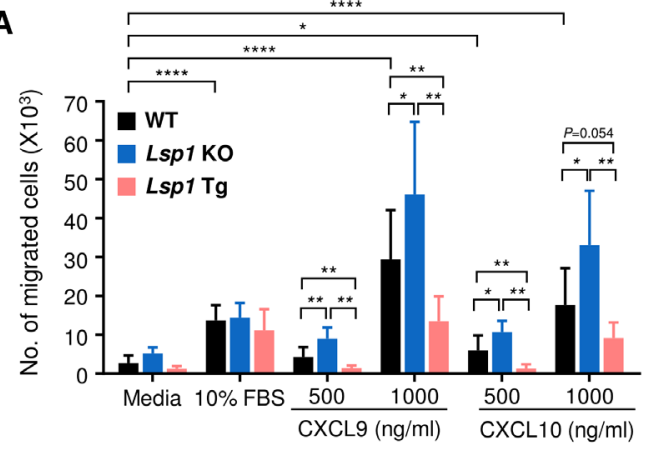

B

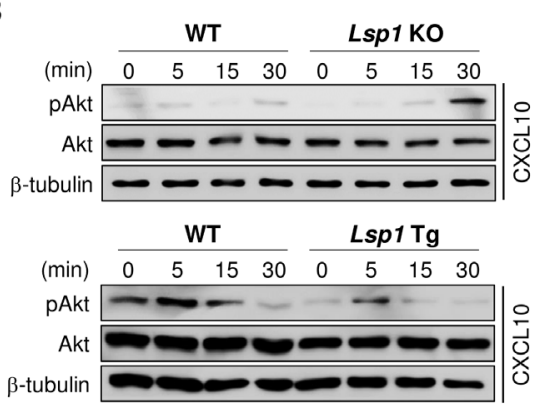

C

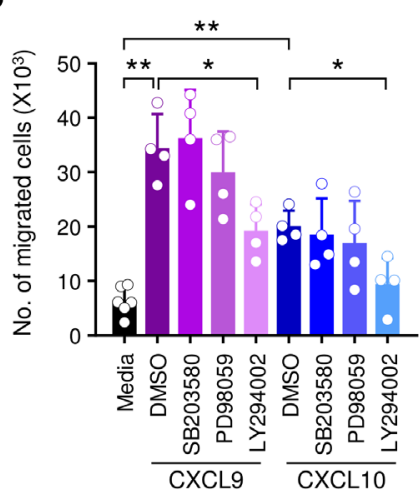

D

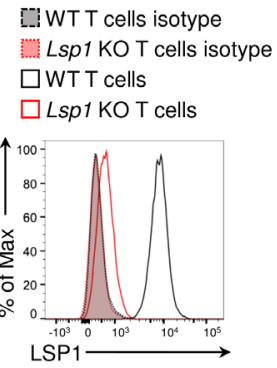

F

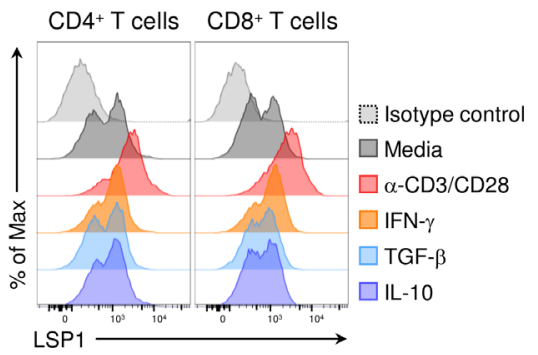

G

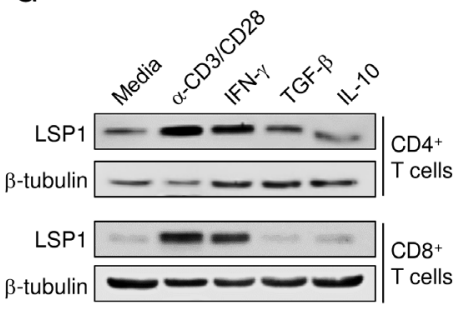

H

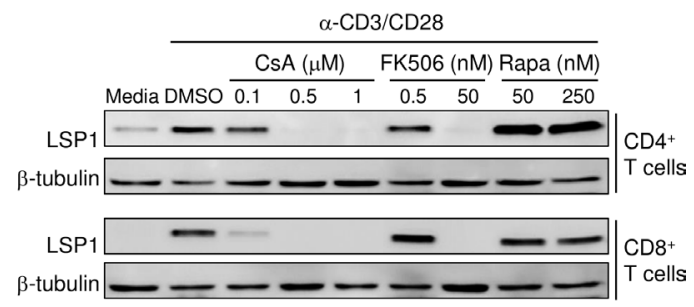

Figure 3 Leukocyte-specific protein 1 (LSP1) expression in T cells and its role in T cell migration. (A) Chemotactic migration of $\mathrm{CD}^{+} T$ cells of wild-type (WT) $(n=13), L s p 1$ knockout $(K O)(n=5)$ and $L s p 1$ Tg mice $(n=9)$. (B) Western blot analysis for phosphorylated Akt (p-Akt) expression. WT, Lsp1 KO and Lsp1 Tg CD8 ${ }^{+}$T cells were treated with CXCL10 (1000 ng/mL) for the indicated time. p-Akt and Akt expression in the cells was determined by western blot analysis. (C) Decreases in WT CD8 ${ }^{+}$ T cell migration by a specific inhibitor of Akt. WT CD8 ${ }^{+}$T cells were treated with p38 MAPK inhibitor (SB203580, $\left.10 \mu \mathrm{M}\right)$, ERK inhibitor (PD98059, $2 \mu \mathrm{M})$ or PI3K/Akt inhibitor (LY294002, $20 \mu \mathrm{M})$ for $30 \mathrm{~min}$. Cell migration induced by CXCL9 $(1000 \mathrm{ng} / \mathrm{mL})$ or CXCL10 (1000 ng/mL) was assayed using a hemocytometer. (D) Specificity of antimouse LSP1 antibody (Ab) used in flow cytometry. (E) LSP1 expression levels in tumor-infiltrating CD4 ${ }^{+} \mathrm{T}$ cells and $\mathrm{CD} 8^{+} \mathrm{T}$ cells. Fifteen days after inoculation of B16 melanoma in WT mice $(n=5)$, tumor-infiltrating leukocytes (TILs) were isolated from tumor tissues. Spleen cells (SPN) of WT mice with tumor inoculation (tumor-challenged SPN, n=5) and those without tumor inoculation (naïve SPN, $n=4$ ) were used as controls. Intracellular LSP1 expression levels were assessed using flow cytometry. ( $F$ and G) Increase in LSP1 expression in T cells by stimulation with anti-CD3/anti-CD28 Abs and interferon-gamma (IFN- $\gamma$ ). WT splenic T cells were stimulated with IFN- $\gamma(10 \mathrm{ng} / \mathrm{mL})$, transforming growth factor- $\beta$ (TGF- $\beta)(2 \mathrm{ng} / \mathrm{mL})$, interleukin (IL)-10 (10 ng/mL) or anti-CD3 plus anti-CD28 Abs $(\alpha-C D 3 / C D 28,1 \mu \mathrm{g} / \mathrm{mL})$ for 72 hours. Intracellular LSP1 expression levels were measured by flow cytometry $(F)$ and western blot analysis (G). (H) Suppression of LSP1 expression by calcineurin inhibitors. WT splenic T cells were stimulated with antiCD3/anti-CD28 Abs $(\alpha-C D 3 / C D 28,1 \mu \mathrm{g} / \mathrm{mL})$ in the absence or presence of ciclosporin $\mathrm{A}$, tacrolimus or rapamycin at the indicated concentrations for 72 hours. LSP1 expression in the cells were measured by western blot analysis. Data in (A to $H)$ are representative of at least three independent experiments or the mean $\pm S D$. P values were determined by unpaired two-tailed t-test. ${ }^{\star} \mathrm{P}<0.05 ;{ }^{* \star} \mathrm{p}<0.01 ;{ }^{* \star *} \mathrm{p}<0.001 ;{ }^{* \star \star *} \mathrm{p}<0.0001$.

enriched by the DEGs upregulated in Lsp1 KO T cells, but leukocyte proliferation and survival failed to show such significance (figure $4 \mathrm{C}$ and online supplemental table 3). GSEA also revealed that the biological processes of 'cell killing' and 'leukocyte-mediated cytotoxicity' were increased in Lsp1 KO T cells (figure 4D), whereas 'negative regulation of cell killing' was decreased (data not shown), which confirms that Lsp1 governs the genes associated with T cell-mediated cytotoxicity. The volcano plots in online supplemental figure 7 show the 18 upregulated 
A

Upregulated DEGs in Lsp1 KO

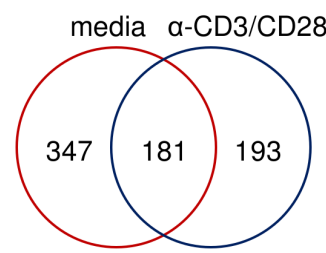

Downregulated DEGs in Lsp1 KO

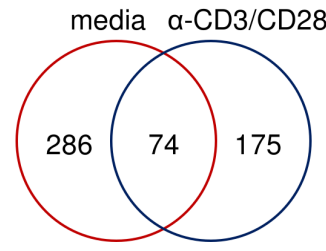

C

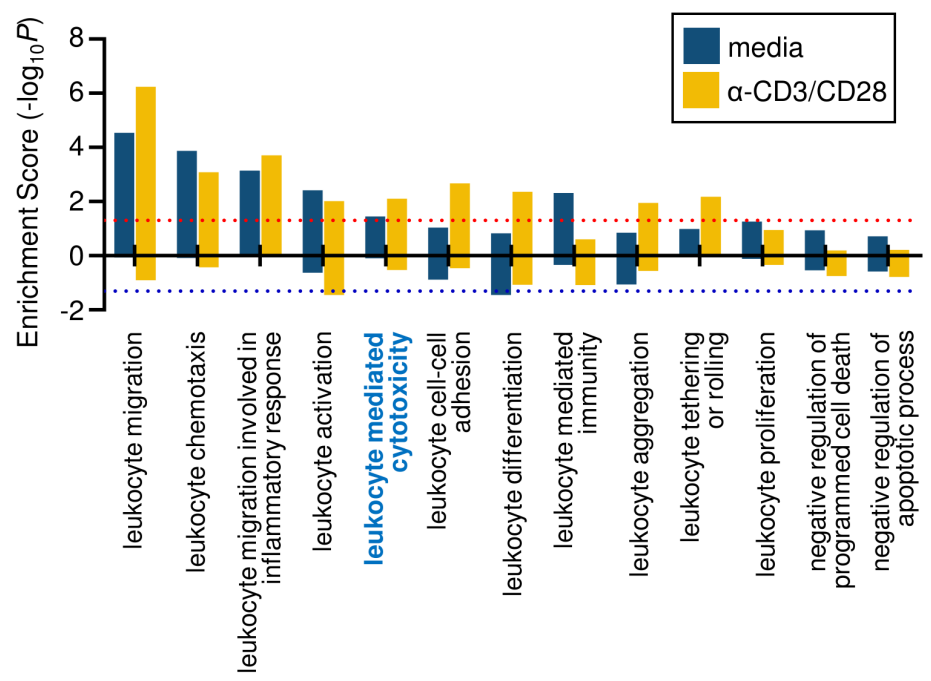

B

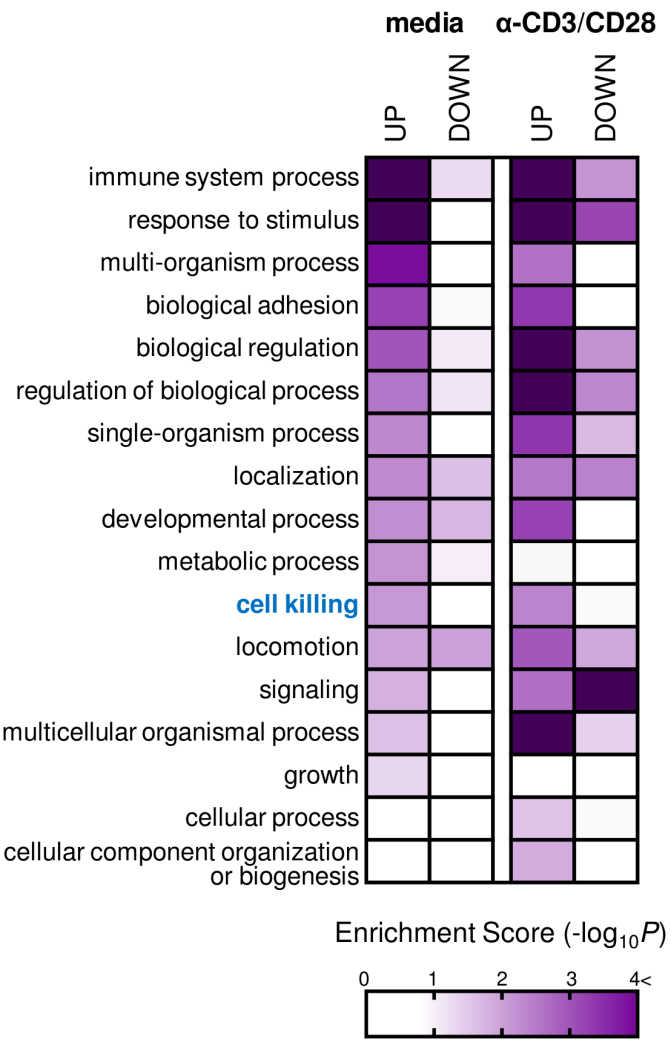

D Cell Killing media a-CD3/CD28
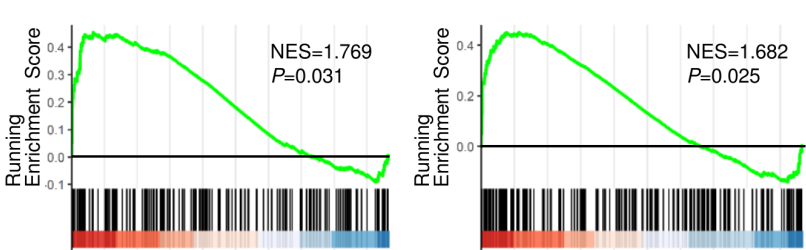

S $=1.682$

D

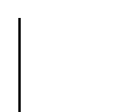

Leukocyte-mediated cytotoxicity

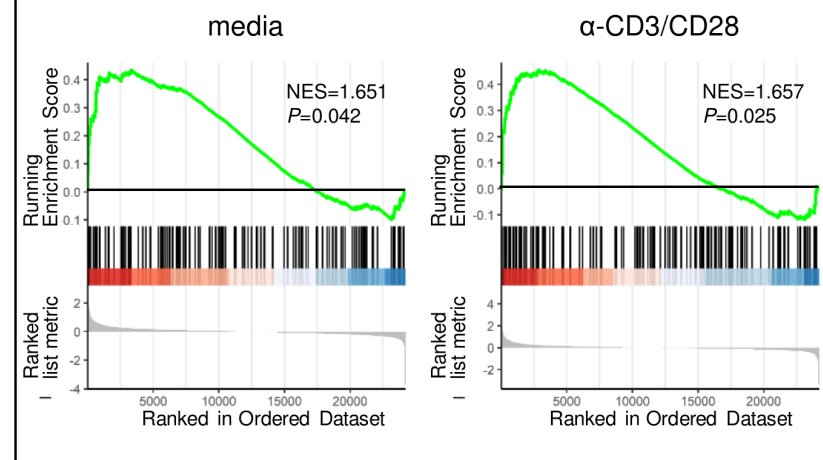

Figure 4 Increased cytotoxicity-related biological processes in leukocyte-specific protein 1 (Lsp1) knockout (KO) T cells. (A) Venn diagram depicting the overlap between the differentially expressed genes (DEGs) in Lsp1 KO T cells compared with wild-type (WT) T cells stimulated media alone and those with anti-CD3/anti-CD28 antibodies (Abs) ( $\alpha$-CD3/CD28) for 6 hours. The RNA was reverse-transcribed, amplified and then hybridized to microarray chips as described in 'Materials and methods' section (GSE75123). (B) Heatmap showing gene ontology biological processes (GOBPs) enriched by upregulated or downregulated DEGs in Lsp1 KO T cells. The color gradient represents the enrichment score defined as $-\log _{10}(\mathrm{p}$ value) for each GOBP. (C) Enrichment score for child GOBPs of 'leukocyte-related biologic processes' and 'cell survival'. Positive value means 'increase' in the each GOBPs and negative value the opposite. The dotted lines indicate the cut-off levels for statistical significance. (D) Gene set enrichment analysis (GSEA) plots of 'cell killing' and 'leukocyte-mediated cytotoxicity' enriched in Lsp1 KO T cells stimulated with media alone or anti-CD3/anti-CD28 Abs. Normalized enrichment scores (NES) and $p$ values are presented in each plot. 
DEGs $(78.2 \%)$ of the 23 involved in 'leukocyte-mediated migration' and 27 upregulated DEGs $(81.8 \%)$ of the 33 involved in 'cell killing'.

Cytotoxicity is one of the essential steps by which tumor-infiltrating T cells suppress tumor growth. ${ }^{32}$ Based on our microarray data, we sought to assess if loss of $L s p 1$ promotes the cytotoxic effector function of $\mathrm{T}$ cells. To this end, we measured the expression levels of IFN- $\gamma$ and TNF- $\alpha$, representative antitumor effector cytokines, ${ }^{28} 33$ in splenic and tumor-infiltrating T cells in WT and Lsp1 KO mice by flow cytometry. Spleen size, the number of splenocytes and the proportion of splenic $\mathrm{CD}^{+}$and $\mathrm{CD}^{+} \mathrm{T}$ cells did not differ between tumor-bearing WT and $L s p 1 \mathrm{KO}$ mice (online supplemental figure 8A-C). In the spleen, the frequencies of TNF- $\alpha^{+}$and IFN- $\gamma^{+}$cells in $\mathrm{CD}^{+}$and $\mathrm{CD}^{+} \mathrm{T}$ cells were also similar between the two groups (online supplemental figure 8D,E). In the tumor, however, they were significantly higher in the infiltrated $\mathrm{CD}^{+}$and $\mathrm{CD}^{+} \mathrm{T}$ cells of $L s p 1 \mathrm{KO}$ mice than in those of WT mice (figure $5 \mathrm{~A}, \mathrm{~B}$ ), suggesting that $L s p 1$ deficiency increases antitumor immunity by inducing TNF- $\alpha^{+}$and IFN- $\gamma^{+}$expression in tumor-infiltrating T cells.

Conversely, the frequencies of TNF- $\alpha^{+}$and/or IFN- $\gamma^{+}$ cells in splenic $\mathrm{CD} 4^{+}$and $\mathrm{CD} 8^{+}$cells were significantly lower in $L s p 1 \mathrm{Tg}$ mice than in WT mice after tumor inoculation (online supplemental figure 9D,E). In tumor tissue, Lsp1-overexpressing $\mathrm{CD} 4^{+}$and $\mathrm{CD}^{+}{ }^{+} \mathrm{T}$ cells also showed markedly reduced frequencies of TNF- $\alpha^{+}$and/or IFN- $\gamma^{+}$cells compared with WT $\mathrm{CD} 4^{+}$and $\mathrm{CD} 8^{+} \mathrm{T}$ cells, respectively (figure $5 \mathrm{C}, \mathrm{D}$ ). As a control, the frequency of IL-2 $2^{+}$cells was not different in Lsp1 Tg and WT mice. Spleen size and splenocyte numbers were also similar between the two groups of mice (online supplemental figure 9A,B). Interestingly, splenic $\mathrm{CD}^{+} \mathrm{T}$ cells of $L s p 1$ Tg mice were less expanded, while splenic $\mathrm{CD} 4^{+} \mathrm{T}$ cells of $L s p 1 \mathrm{Tg}$ mice were more expanded than those of WT mice (online supplemental figure 9C). Overall, these results suggest that Lsp1 overexpression in $\mathrm{T}$ cells promotes melanoma growth through downregulation of TNF- $\alpha^{+}$ and IFN- $\gamma^{+}$production by $\mathrm{CD} 8^{+} \mathrm{T}$ cells, in addition to a marked decrease in infiltrated $\mathrm{CD} 8^{+} \mathrm{T}$ cells.

\section{Lsp1 depletion potentiates antitumor effect of anti-PD-1 antibody}

On the basis of the aforementioned data, we postulated that Lsp1-deficient $\mathrm{T}$ cells more effectively suppress tumor growth due to their increased capacity for cytotoxicity as well as T cell trafficking. To address whether Lsp1manipulated (eg, gene-edited) $\mathrm{T}$ cells have therapeutic potential and to confirm that the $L s p 1$ gene in T cells is required for melanoma growth, we performed adoptive transfer experiments using $L s p 1 \mathrm{KO}$ and $L s p 1 \mathrm{Tg} \mathrm{T}$ cells in Rag1 KO mice, which are deficient in mature $\mathrm{T}$ and $\mathrm{B}$ cells. ${ }^{34}$ Prior to the adoptive transfer, we confirmed that Lsp1 KO T cells and $L s p 1 \mathrm{Tg} \mathrm{T}$ cells had a similar ratio of $\mathrm{CD} 4 / \mathrm{CD} 8$ in $\mathrm{CD}^{+} \mathrm{T}$ cells (figure $6 \mathrm{~A}$ ). As shown in figure 6B, Lsp1-deficient $\mathrm{T}$ cells more strongly repressed tumor progression in Rag1 KO mice challenged with
B16 melanoma as compared with Lsp1-overexpressing T cells and vehicle alone (without mature T cells), which confirms that loss of $L s p 1$ in T cells specifically mediates the antitumor effect.

Anti-PD-1 blockade has been successfully used as an immunotherapy for a variety of advanced cancers, including melanoma. ${ }^{35}$ Finally, we investigated whether the antitumor effect of $L s p 1$ deficiency can be further improved by the administration of anti-PD-1 Ab since the two approaches have different antitumor mechanisms: improvement of $\mathrm{T}$ cell trafficking versus blockade of inhibitory immune checkpoints, respectively. To this end, WT and Lsp1 KO mice were subcutaneously challenged with B16 melanoma cells on day 0 followed by anti-PD-1 $\mathrm{Ab}$ or matched isotype control $\mathrm{Ab}$ on days 3, 6, 9 and 12 (figure 6C). As expected, treatment with anti-PD-1 $\mathrm{Ab}$ substantially reduced melanoma growth in WT mice (figure 6D). Of note, Lsp1 KO mice treated with anti-PD-1 blockade showed a greater antitumor effect than WT mice without or with anti-PD-1 Ab (figure 6D), indicating that the extent of the antitumor effect of $L s p 1$ deficiency is maintained irrespective of anti-PD- $1 \mathrm{Ab}$ treatment. In Lsp1 KO mice treated with anti-PD-1 Ab, the contribution of anti-PD-1 Ab treatment and Lsp1 deficiency to tumor suppression was $59.6 \%$ and $40.4 \%$, respectively, as estimated by the degree of decrease in mean tumor volume 14 days after the melanoma inoculation (figure 6D).

Taken together, these observations suggest that genetic ablation of $L s p 1$ in T cells is a promising strategy to boost the therapeutic efficacy of immune checkpoint inhibitors for melanoma, including anti-PD-1 Ab.

\section{DISCUSSION}

Evidence has emerged that the extent of intratumoral $\mathrm{T}$ cell infiltration in the tumor mass is one of the major factors determining the efficacy of tumor immunotherapy. ${ }^{1226}$ In the pathology of tumor, TME constructs physical barriers and activates immunosuppressive networks so that $\mathrm{T}$ cell infiltration does not occur in the tumor beds. ${ }^{831} 36$ Therefore, it is essential to develop a strategy that facilitates $\mathrm{T}$ cell infiltration into the center of tumors. However, current anticancer immunotherapies mainly focus on reinvigorating pre-existing $\mathrm{T}$ cells in the tumor using immune checkpoint blockades, while strategies for accelerating $\mathrm{T}$ cell trafficking to the center of tumors are poorly developed. ${ }^{4}$

Here, we provide novel mechanisms of LSP1 regulation of tumor growth and $\mathrm{T}$ cell infiltration in the TME. We demonstrated first that $L s p 1$ deficiency reduces the growth of B16 melanoma and enhances the infiltration of immune cells into tumor sites in mice. The effect was reproduced in an MC38 colon cancer model, indicating that LSP1 regulation of tumor progression is not limited to B16 melanoma. We also found that tumor-infiltrating T cells in WT mice were localized along the border of B16 melanoma, but rarely found in the center of a tumor. As a result, in WT mice, the distribution of immune cells, particularly $\mathrm{T}$ 
A

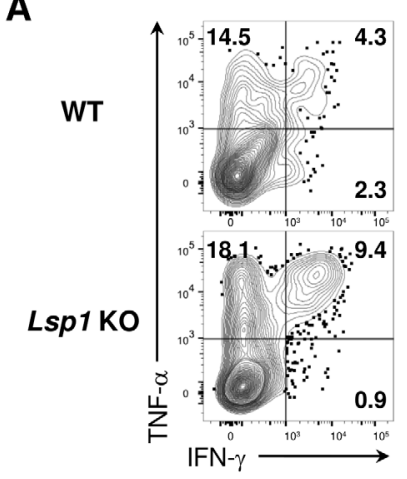

B

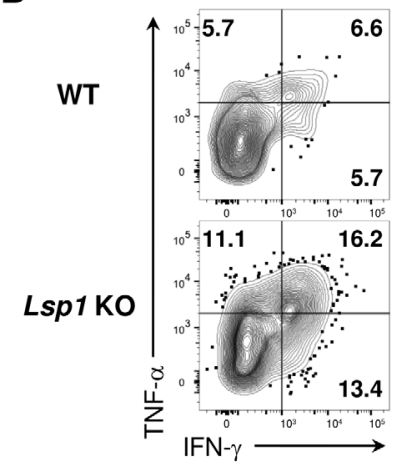

C

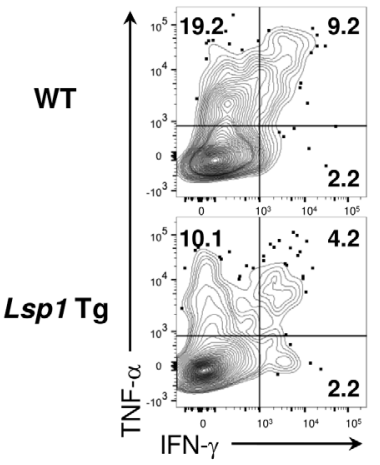

D

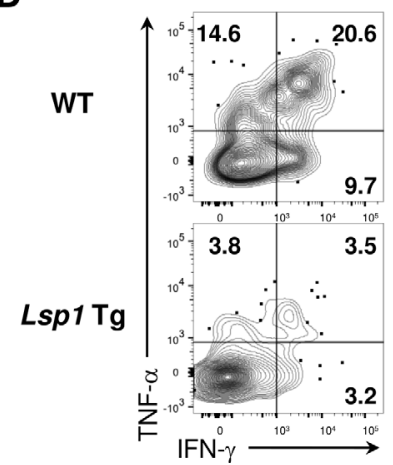

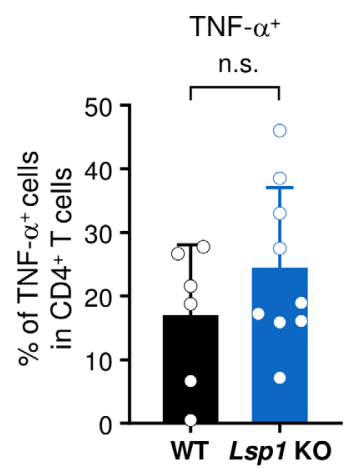
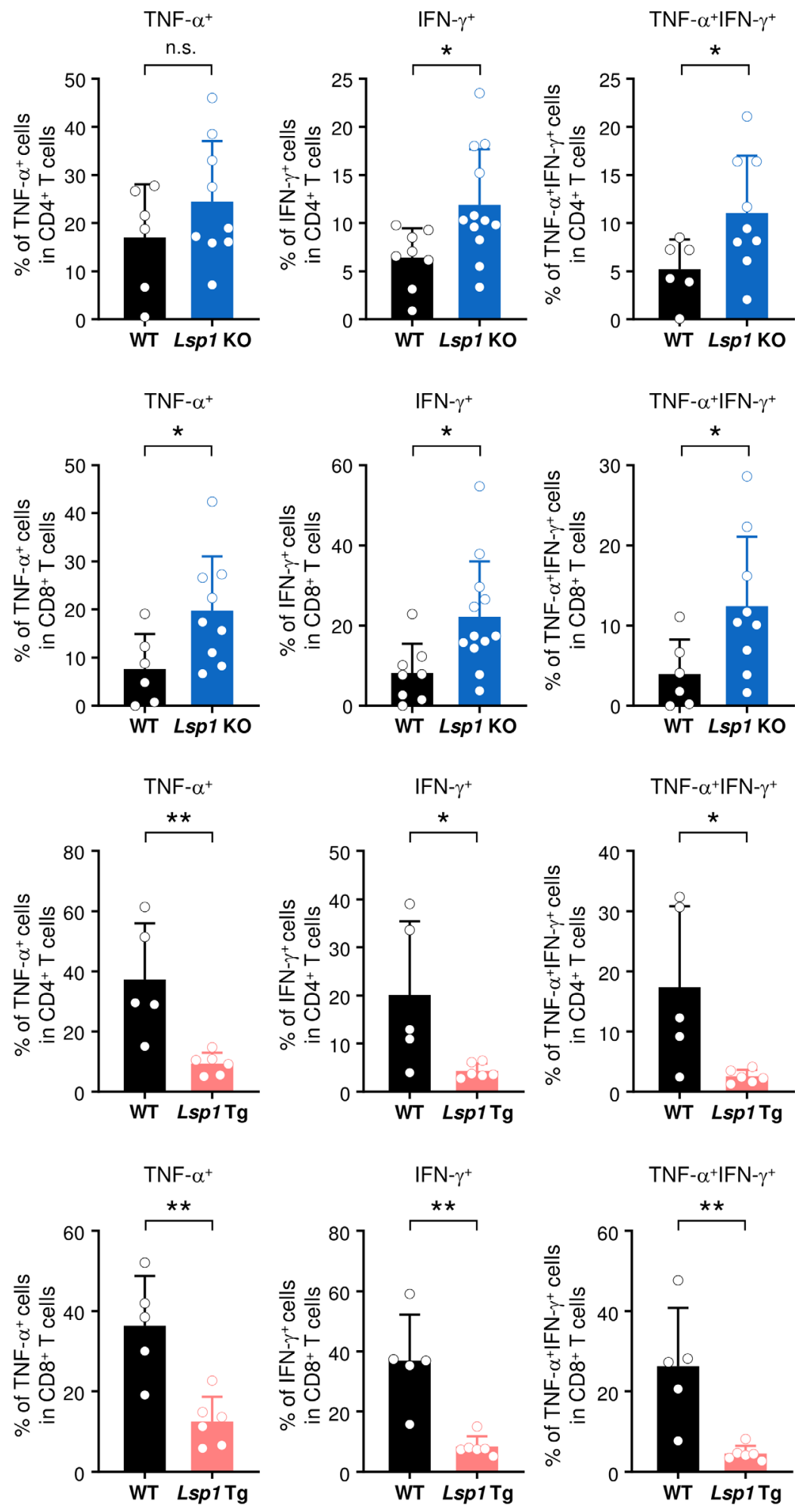

Figure 5 Leukocyte-specific protein 1 (LSP1) regulation of tumor necrosis factor-alpha (TNF- $\alpha$ ) and interferon-gamma (IFN- $\gamma$ ) expression in tumor-infiltrating T cells. (A and B) Expression of TNF- $\alpha$ and IFN- $\gamma$ in tumor-infiltrating T cells of $L s p 1$ knockout (KO) mice. Tumor-infiltrating leukocytes (TILs) were isolated from B16 melanoma-challenged wild-type (WT) ( $\mathrm{n}=6-8)$ and Lsp1 $\mathrm{KO}$ mice $(\mathrm{n}=9-12)$ and then stimulated with phorbol-12-myristate-13-acetate (PMA) $(50 \mathrm{ng} / \mathrm{mL})$ and lonomycin $(500 \mathrm{ng} / \mathrm{mL})$ in the presence of GolgiPlug for 4 hours. Expression of TNF- $\alpha$ and IFN- $\gamma$ in $\mathrm{CD}_{4}^{+}(\mathrm{A})$ and $\mathrm{CD} 8^{+}$T cells (B) was assayed by intracellular flow cytometry as described in 'Materials and methods' section. (C and D) Expression of TNF- $\alpha$ and IFN- $\gamma$ in tumor-infiltrating T cells of $L s p 1$ transgenic $(T g)(n=5)$ and WT mice $(n=6)$. Intracellular cytokine staining was performed with TILs isolated from the two groups of mice, as described in (A and B). Contour plots shown on the left of (A-D) are representative data. The frequencies (\%) of IFN- $\gamma^{+}$and/or TNF- $\alpha^{+}$cells in $\mathrm{CD}^{+}$and $\mathrm{CD} 8^{+} \mathrm{T}$ cells are presented in the bar graphs as the mean $\pm \mathrm{SD}$. $\mathrm{P}$ values were determined by unpaired two-tailed t-test. n.s., not significant. ${ }^{*} \mathrm{P}<0.05 ;{ }^{* *} \mathrm{p}<0.01$. 
A

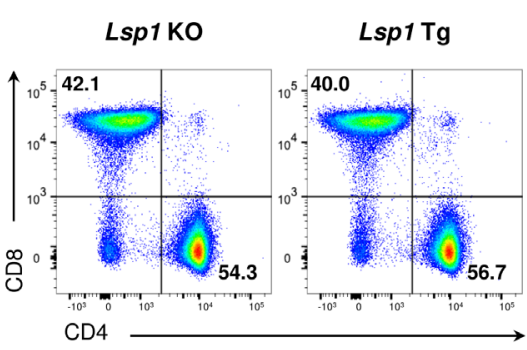

C

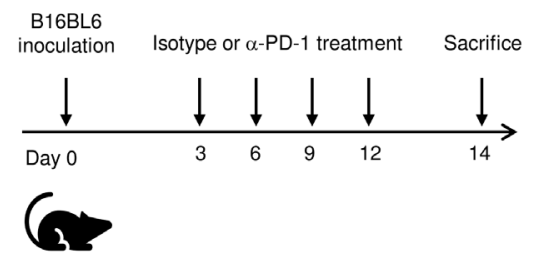

WT or Lsp1 KO

E
B

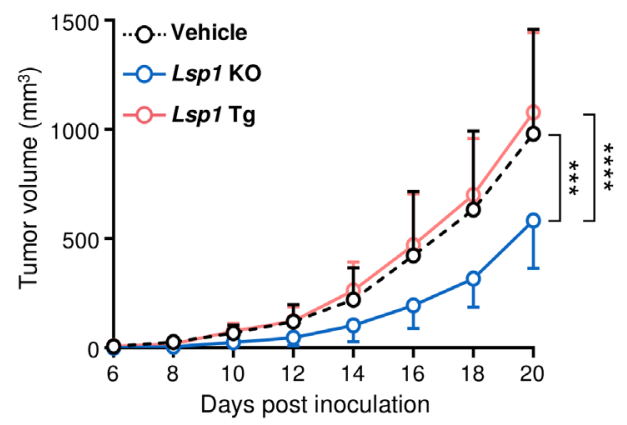

D

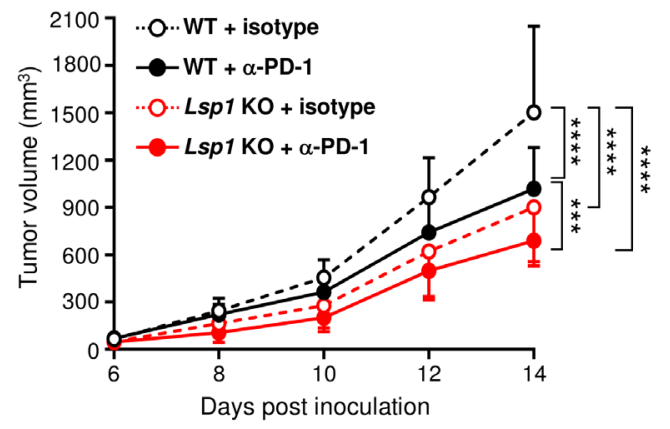

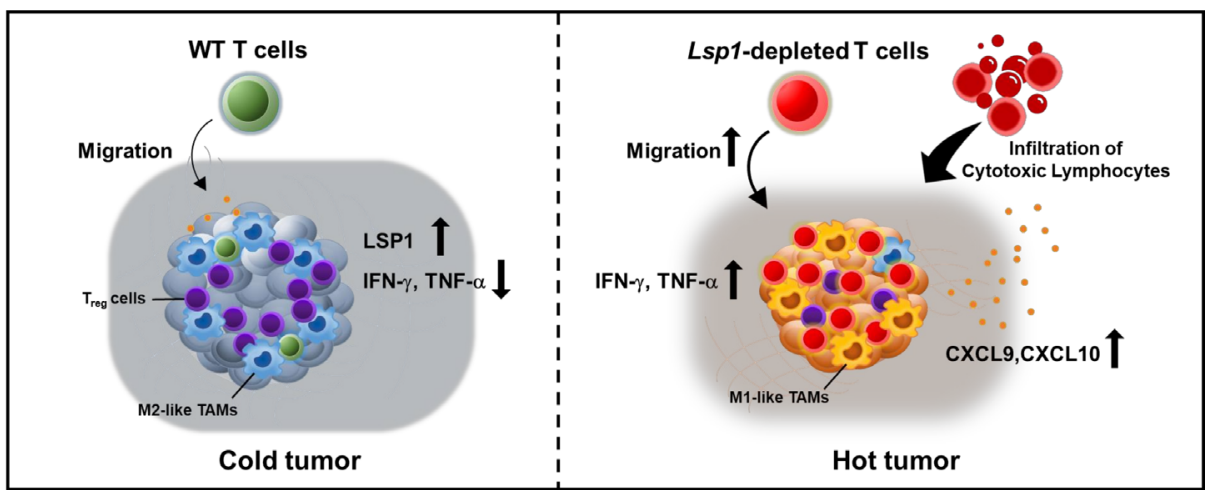

Figure 6 Therapeutic implications of leukocyte-specific protein 1 (LSP1) depletion in tumor progression. (A and B) Adoptive transfer of $L s p 1$ knockout (KO) or $L s p 1$ transgenic $(\mathrm{Tg}) \mathrm{T}$ cells to Rag1 KO mice. Rag1 KO mice were inoculated subcutaneously with B16 melanoma on day 0 . The day after tumor inoculation, $1 \times 10^{7}$ splenic CD3 ${ }^{+} \mathrm{T}$ cells isolated from $L s p 1 \mathrm{KO}$ or $L s p 1 \mathrm{Tg}$ mice were intravenously injected into tumor-bearing Rag1 $\mathrm{KO}$ mice. The ratio of $\mathrm{CD} 4^{+} / \mathrm{CD} 8^{+} \mathrm{T}$ cells in the donor cells was assessed by flow cytometry prior to the injection (A). Growth curves of B16 melanoma in Rag1 KO mice injected with vehicle alone $(n=9)$, $L s p 1$ KO T cells $(n=7)$ and $L s p 1$ Tg T cells $(n=6)$ are presented in $(B)$ as the mean $\pm S D$ at the indicated time points. (C and D) Potentiation of antitumor effect of antiprogrammed cell death protein 1 (PD-1) antibody by Lsp1 deficiency. Lsp1 KO and WT mice were subcutaneously inoculated with B16 melanoma cells and then intraperitoneally injected with $10 \mathrm{mg} / \mathrm{kg}$ of either isotype control antibodies (Abs) (isotype, $n=7$ mice per genotype) or anti-PD-1 Abs ( $\alpha$-PD-1, $n=10$ mice per genotype) at the time points indicated in (C). Tumor growth was monitored for 14 days in the two groups of mice (D). The data shown in (B) and (D) represent the mean $\pm S D$ of the two independent experiments. $P$ values were determined by two-way analysis of variance analysis (ANOVA) with Tukey's multiple comparison. ${ }^{* * *} \mathrm{p}<0.001 ;{ }^{* \star *} \mathrm{p}<0.0001$. (E) Hypothetical model of the reconstruction of the tumor microenvironments (TME) by Lsp1-deficient T cells. LSP1 expression in T cells can be upregulated by stimulation of T cell receptors and interferon-gamma (IFN- $\gamma$ ) when exposed to the TME (figure 3F,G). Elevated LSP1 expression, in turn, may impair the antitumor effector functions of T cells, including cell migration (figure 3A), cytotoxicity (figure 4) and IFN- $\gamma$ and tumor necrosis factor-alpha (TNF- $\alpha$ ) production (figure 5). In such instances, T cell-mediated elimination of tumors is downregulated, ${ }^{31}$ which hampers additional release of tumor antigens and further activation of T cells, resulting in a negative feedback loop for the immunosuppressive TME. ${ }^{38}{ }^{39}$ Conversely, if $L s p 1$-depleted T cells are generated using gene-editing technology and adoptively transferred to subjects with tumors, they seem to rapidly migrate and infiltrate into the tumor mass (figures 1 and $3 \mathrm{~A}$ ) and actively retard tumor growth (figure 6B) by producing large amounts of cytotoxic mediators, such as IFN- $\gamma$ and TNF- $\alpha$ (figure 5). Consequently, Lsp1-edited T cells can induce the release of tumor antigens into the TME and augment secretion of IFN- $\gamma$-inducible chemokines, such as CXCL9 and CXCL10. ${ }^{38} 3945$ These chemokines, in turn, recruit more cytotoxic T cells (figure 3A), generating a positive feedback loop for formation of an immunocompetent TME and ultimately leading to the conversion of TMEs from 'infiltrative excluded (cold tumor)' to 'infiltrated-inflamed (hot tumor)'. ${ }^{26}{ }^{45}$ 
cells, showed a representative 'infiltrated-excluded' type of tumor, in which Ly6C ${ }^{\text {low }} \mathrm{F} 4 / 80^{\text {high }}$ TAMs prevent $\mathrm{CD} 8^{+} \mathrm{T}$ cell infiltration into the tumor core. ${ }^{26}$ By contrast, in $L s p 1 \mathrm{KO}$ mice, $\mathrm{CD}^{+}$and $\mathrm{CD} 8^{+} \mathrm{T}$ cells were frequently found in the tumor core and their distribution represents an 'infiltratedinflamed' tumor phenotype, in which cytotoxic T cells are heavily infiltrated and have potent antitumor activity. ${ }^{26}$

It was not clear whether the reduction of tumor growth in $L s p 1 \mathrm{KO}$ mice stemmed from the increased infiltration of only $\mathrm{CD}^{+} \mathrm{T}$ cells in tumor tissue, since the frequency of $\mathrm{CD} 11 \mathrm{~b}^{+} \mathrm{Ly} 6 \mathrm{C}^{\text {low }} \mathrm{F} 4 / 80^{\text {high }}$ TAMs was also substantially decreased in the tumors of $L s p 1 \mathrm{KO}$ mice. To address this issue, we created transgenic mice in which $L s p 1$ is overexpressed specifically in $\mathrm{T}$ cells ( $L s p 1 \mathrm{Tg}$ mice). In sharp contrast with Lsp1 KO mice, Lsp1 Tg mice showed an increase in B16 melanoma growth along with a remarkable decrease in $\mathrm{CD}^{+} \mathrm{T}$ cell infiltration into the tumor sites as compared with WT mice, which indicates that Lsp1overexpressing $\mathrm{T}$ cells directly suppress tumor growth. As expected, the frequencies of other types of immune cells did not differ between $L s p 1 \mathrm{Tg}$ and WT mice, suggesting that the decrease in $\mathrm{CD}^{+} \mathrm{T}$ cells, rather than other types of TILs, in the tumor mass is one of the primary mechanisms driving the differential growth of B16 melanoma between the two groups.

Mechanistically, our data suggest how LSP1 regulates B16 melanoma growth. In vitro functional tests demonstrated that Lsp1-deficient $\mathrm{CD}^{+}{ }^{\mathrm{T}}$ cells had increased chemotactic activity via the p-Akt signaling pathway on CXCL9 and CXCL10 stimulation, the major chemokines involved in $\mathrm{T}$ cell trafficking towards tumor sites, whereas Lsp1overexpressing $\mathrm{CD}^{+} \mathrm{T}$ cells showed the opposite response. This confirms that LSP1, an F-actin binding molecule, ${ }^{10}$ negatively regulates $\mathrm{T}$ cell migration. ${ }^{13}$ Intriguingly, gene expression profiling of $L s p 1 \mathrm{KO} \mathrm{T}$ cells revealed that the biological processes of 'cell killing' and 'leukocyte-mediated cytotoxicity' were significantly enriched by the DEGs. Concurrently, the expression of IFN- $\gamma$ and TNF- $\alpha$, major cytotoxic effector cytokines, in $\mathrm{CD} 4^{+}$and $\mathrm{CD} 8^{+} \mathrm{T}$ cells was higher in B16 melanoma of Lsp1 KO mice than in control mice. Conversely, it was markedly decreased in tumors of Lsp1 Tg mice, which supports our microarray data. Taken together, we believe that at least two possible mechanisms contribute to LSP1 regulation of tumor growth: 1) altered migration and infiltration of $\mathrm{T}$ cells into the tumor and 2) changes in the production of antitumor effector cytokines by $\mathrm{CD}^{+} \mathrm{T}$ cells.

Our data demonstrated that LSP1 directly controls the migration of $\mathrm{CD}^{+} \mathrm{T}$ cells via an intracellular signal of p-Akt on CXCL9/10 ligation. However, a recent study reported that $\mathrm{CD} 4^{+} \mathrm{T}$ cells influence survival and migration of $\mathrm{CD}^{+}{ }^{+} \mathrm{T}$ cells. ${ }^{37}$ Thus, we wondered what the specific contribution of $L s p 1$-deficient $\mathrm{CD} 4^{+} \mathrm{T}$ cells is for $\mathrm{CD}^{+} \mathrm{T}$ cells migration. To address this question, WT $\mathrm{CD}^{+} \mathrm{T}$ cells were co-cultured with WT or Lsp1 KO $\mathrm{CD} 4^{+} \mathrm{T}$ cells for 3 days in the presence of anti-CD3 Ab, and then their survival, proliferation and migration were examined using flow cytometry. As a result, survival and proliferation of $\mathrm{CD}^{+} \mathrm{T}$ cells did not differ between co-culture of $\mathrm{CD}^{+} \mathrm{T}$ cells with $L s p 1 \mathrm{KO} \mathrm{CD} 4^{+} \mathrm{T}$ cells and that with WT $\mathrm{CD} 4^{+} \mathrm{T}$ cells (online supplemental figure $10 \mathrm{~A}, \mathrm{~B})$. Migration of $\mathrm{CD}^{+} \mathrm{T}$ cells induced by CXCL9 and CXCL10 showed similar results (online supplemental figure 10C). Therefore, we presume that LSP1 expression level in $\mathrm{CD} 4^{+} \mathrm{T}$ cells has no effect on the survival, proliferation and migration of $\mathrm{CD} 8^{+} \mathrm{T}$ cells.

Our work may have uncovered a novel mechanism by which a tumor evades the host immune system. We found increased LSP1 expression in tumor-infiltrating T cells that are antigen-experienced in an in vivo melanoma model. In accordance with this, LSP1 levels in $\mathrm{CD} 4^{+}$and $\mathrm{CD}^{+} \mathrm{T}$ cells were increased by TCR stimulation in a calcineurin-dependent manner. We also demonstrated that LSP1 expression in T cells was induced by the proinflammatory cytokine IFN- $\gamma$. Given that the release of tumor-associated neoantigens occurs in the TME via the cancer-immunity cycle, ${ }^{38}$ the released tumor antigens could activate tumor-infiltrating $\mathrm{T}$ cells to upregulate LSP1 expression. It is plausible that IFN- $\gamma$, which is highly produced by $\mathrm{T}$ cells challenged with antigens, may be one of the mediators of such upregulation or may further increase LSP1 expression after activation of TCR. Taken together, elevated LSP1 expression levels induced by tumor-associated antigens or IFN- $\gamma$ may hamper further migration of tumor-infiltrating $\mathrm{T}$ cells inside the tumor mass, resulting in establishment of the 'infiltrated-excluded' tumor phenotype. ${ }^{26}$

Insufficient $\mathrm{T}$ cell trafficking into the tumor sites, especially in solid tumors, reduces the therapeutic efficacy of immune checkpoint blockades. ${ }^{39}$ In the present study, we demonstrated that $L s p 1 \mathrm{KO}$ T cells more effectively suppressed melanoma growth than $L s p 1 \mathrm{Tg} \mathrm{T}$ cells when adoptively transferred into Rag $1 \mathrm{KO}$ mice, which suggests that $L s p 1$-manipulated T cells have therapeutic potential. Based on these findings, we hypothesized that an increase in $\mathrm{T}$ cell trafficking by $L s p 1$ ablation, which can be practically achieved by gene editing using CRISPR-Cas $9,{ }^{40}$ would improve the efficacy of anti-PD-1 blockade. As expected, suppression of melanoma growth was more pronounced in Lsp1 KO mice than in WT mice when treated with PD-1 Ab. Given that anti-PD-1 therapy has only a modest influence on the number of TILs in melanoma, ${ }^{41}{ }^{42}$ the growth of melanoma might be additively regressed by the combined effects of 1) increased T cell-mediated cytotoxicity by inhibiting PD-1 and/or LSP1 and 2) enhanced T cell motility by $L s p 1$ deficiency. Considering that melanoma is resistant to anti-PD-1 therapy ${ }^{43}$ our data provide new evidence that adoptive cell therapy using $L s p 1$-edited T cells together with anti-PD-1 blockade might be a promising strategy for more effectively treating solid tumors, such as melanoma.

In summary, Lsp1 KO mice showed decreased growth of B16 melanoma and increased infiltration of T cells, including $\mathrm{CD}^{+} \mathrm{T}$ cells, in the tumor mass, and these effects were completely reversed in T cell-specific $L s p 1$ 
Tg mice. The effect of $L s p 1$ deficiency was reproduced in MC38 colon cancer. LSP1 expression was elevated in tumor-infiltrating $\mathrm{T}$ cells and could be induced by the stimulation of $\mathrm{T}$ cells with TCR and IFN- $\gamma$. The CD $8^{+} \mathrm{T}$ cells of $L s p 1 \mathrm{KO}$ mice had greater migratory capacity in response to CXCL9 and CXCL10 than those of WT mice, which was mediated through an intracellular signal of p-Akt; Lsp1 Tg CD8 ${ }^{+} \mathrm{T}$ cells showed the opposite effect. Interestingly, gene expression profiling of Lsp1 KO T cells revealed increased cytotoxicity, which seems to be associated with higher expression of IFN- $\gamma$ and TNF- $\alpha$ in T cells. Adoptive transfer of Lsp1 KO T cells to Rag1 $\mathrm{KO}$ mice was more effective in repressing melanoma growth than transfer of Lsp1 Tg T cells. Moreover, Lsp1 KO mice showed a greater antitumor effect than WT mice when treated with anti-PD-1 Ab. Collectively, these results show that LSP1 regulates the growth of B16 melanoma in mice, presumably by affecting migration and infiltration of $\mathrm{T}$ cells into tumor sites and by modulating the production of antitumor effector cytokines by $\mathrm{T}$ cells. We anticipate that $L s p 1$ depletion in T cells may convert immune-deficient 'cold' tumors to immunesufficient 'hot' tumors, as depicted in figure $6 \mathrm{E}$, which may serve as an effective strategy to overcome the current limitations of $\mathrm{T}$ cell-based immunotherapy and to improve the efficacy of immune checkpoint blockades and tumor vaccination ${ }^{44}$ for solid tumors.

\section{CONCLUSION}

Our data provide the first evidence that LSP1 in T cells regulates the progression of melanoma. This study also demonstrates that genetic ablation of $L s p 1$ in T cells improves antitumor immune response to B16 melanoma, probably by promoting $\mathrm{T}$ cell migration into tumor sites and by upregulating IFN- $\gamma$ and TNF- $\alpha$ expression in T cells, which ultimately leads to the conversion of TMEs from 'immuneresistant' to 'immune-susceptible'. Therefore, adoptive cell therapy using LSP1 gene-edited T cells may be an innovative strategy for treating solid tumors, including melanoma.

Acknowledgements The authors would like to thank all members of the Center for Integrative Rheumatoid Transcriptomics and Dynamics for their help and advice.

Contributors RK and NL performed the experiments and drafted the paper. C-SC, $\mathrm{NL}$ and W-UK designed the experiments and interpreted the results. B-KH analyzed the microarray data. K-GL performed western blot analysis for intracellular signaling pathways. EC performed adoptive T cell transfer into Rag1 KO mice. LS kindly provided the Lsp1 K0 mice. W-UK edited the paper and supervised the research. All authors commented on the manuscript.

Funding This work was supported by grants from the National Research Foundation of Korea (NRF) funded by the Ministry of Education, Science and Technology (2015R1A3A2032927 to W-UK, 2018R1A1A3A04078559 to NL, 2020R1I1A1A01071974 to B-KH), and Research Center of Dong-A ST., Ltd. (to NL).

\section{Competing interests None declared.}

\section{Patient consent for publication Not required.}

Ethics approval All procedures for animal research were performed in accordance with the Laboratory Animals Welfare Act, the Guide for the Care and Use of Laboratory Animals and the Guidelines and Policies for Rodent Experiments provided by the Institutional Animal Care and Use Committee of The Catholic University of Korea (approval number: CUMS-2018-0195-04, 2019-0206-01).
Provenance and peer review Not commissioned; externally peer reviewed.

Data availability statement Data are available on reasonable request. None.

Open access This is an open access article distributed in accordance with the Creative Commons Attribution 4.0 Unported (CC BY 4.0) license, which permits others to copy, redistribute, remix, transform and build upon this work for any purpose, provided the original work is properly cited, a link to the licence is given, and indication of whether changes were made. See https://creativecommons.org/ licenses/by/4.0/.

\section{ORCID iD}

Wan-Uk Kim http://orcid.org/0000-0001-8224-8496

\section{REFERENCES}

1 Fridman $\mathrm{WH}$, Zitvogel L, Sautès-Fridman $\mathrm{C}$, et al. The immune contexture in cancer prognosis and treatment. Nat Rev Clin Oncol 2017;14:717-34.

2 Fridman WH, Pagès F, Sautès-Fridman C, et al. The immune contexture in human tumours: impact on clinical outcome. Nat Rev Cancer 2012;12:298-306.

3 Teng MWL, Ngiow SF, Ribas A, et al. Classifying cancers based on T-cell infiltration and PD-L1. Cancer Res 2015;75:2139-45.

$4 \mathrm{Lim}$ WA, June $\mathrm{CH}$. The principles of engineering immune cells to treat cancer. Cell 2017;168:724-40.

5 Maude SL, Frey N, Shaw PA, et al. Chimeric antigen receptor T cells for sustained remissions in leukemia. $N$ Engl J Med 2014;371:1507-17

6 Mirzaei HR, Rodriguez A, Shepphird J, et al. Chimeric antigen receptors $T$ cell therapy in solid tumor: challenges and clinica applications. Front Immunol 2017;8:8.

7 Slaney CY, Kershaw MH, Darcy PK. Trafficking of T cells into tumors. Cancer Res 2014;74:7168-74.

8 Quail DF, Joyce JA. Microenvironmental regulation of tumor progression and metastasis. Nat Med 2013;19:1423-37.

9 Caruana I, Savoldo B, Hoyos V, et al. Heparanase promotes tumor infiltration and antitumor activity of CAR-redirected T lymphocytes. Nat Med 2015;21:524-9.

10 Jongstra-Bilen J, Jongstra J. Leukocyte-Specific protein 1 (LSP1): a regulator of leukocyte emigration in inflammation. Immunol Res 2006;35:65-74

11 Jongstra-Bilen J, Misener VL, Wang C, et al. Lsp1 modulates leukocyte populations in resting and inflamed peritoneum. Blood 2000;96:1827-35.

12 Wang C, Hayashi H, Harrison R, et al. Modulation of Mac-1 (CD11b/ CD18)-mediated adhesion by the leukocyte-specific protein 1 is key to its role in neutrophil polarization and chemotaxis. $J$ Immunol 2002;169:415-23.

13 Hwang S-H, Jung S-H, Lee S, et al. Leukocyte-Specific protein 1 regulates T-cell migration in rheumatoid arthritis. Proc Natl Acad Sci U S A 2015;112:E6535-43.

14 Easton DF, Pooley KA, Dunning AM, et al. Genome-Wide association study identifies novel breast cancer susceptibility loci. Nature 2007;447:1087-93.

15 Turnbull C, Ahmed S, Morrison J, et al. Genome-Wide association study identifies five new breast cancer susceptibility loci. Nat Genet 2010;42:504-7.

16 Chen H, Qi X, Qiu P, et al. Correlation between LSP1 polymorphisms and the susceptibility to breast cancer. Int J Clin Exp Pathol 2015;8:5798-802.

17 Zeng S-X, Zhu Y, Ma A-H, et al. The phosphatidylinositol 3-kinase pathway as a potential therapeutic target in bladder cancer. Clin Cancer Res 2017;23:6580-91.

18 Jin SY, Choi JS, Choi YL, et al. Identification of leukocyte-specific protein 1-positive cells: a clue to the cell of origin and a marker for the diagnosis of dermatofibroma. Ann Dermatol 2015;27:157-62.

19 Nalesnik MA, Tseng G, Ding Y, et al. Gene deletions and amplifications in human hepatocellular carcinomas: correlation with hepatocyte growth regulation. Am J Pathol 2012;180:1495-508.

20 Koral K, Paranjpe S, Bowen WC, et al. Leukocyte-Specific protein 1: a novel regulator of hepatocellular proliferation and migration deleted in human hepatocellular carcinoma. Hepatology 2015;61:537-47.

21 Flister MJ, Bergom C. Genetic modifiers of the breast tumor microenvironment. Trends Cancer 2018;4:429-44.

22 Cao J-Y, Guo Q, Guan G-F, et al. Elevated lymphocyte specific protein 1 expression is involved in the regulation of leukocyte migration and immunosuppressive microenvironment in glioblastoma. Aging 2020;12:1656-84. 
23 Sabbagh L, Andreeva D, Laramée GD, et al. Leukocyte-Specific protein 1 links TNF receptor-associated factor 1 to survival signaling downstream of 4-1BB in T cells. J Leukoc Biol 2013;93:713-21.

24 Yu G, Wang L-G, Han Y, et al. clusterProfiler: an R package for comparing biological themes among gene clusters. OMICS 2012;16:284-7.

25 Galluzzi L, Chan TA, Kroemer G, et al. The hallmarks of successful anticancer immunotherapy. Sci Transl Med 2018;10. doi:10.1126/ scitranslmed.aat7807. [Epub ahead of print: 19 Oct 2018]

26 Binnewies M, Roberts EW, Kersten K, et al. Understanding the tumor immune microenvironment (time) for effective therapy. Nat Med 2018;24:541-50.

27 Nagarsheth N, Wicha MS, Zou W. Chemokines in the cancer microenvironment and their relevance in cancer immunotherapy. Nat Rev Immunol 2017;17:559-72.

28 Chow MT, Ozga AJ, Servis RL, et al. Intratumoral activity of the CXCR3 chemokine system is required for the efficacy of anti-PD-1 therapy. Immunity 2019;50:1498-512.

29 Smit MJ, Verdijk P, van der Raaij-Helmer EMH, et al. Cxcr3-Mediated chemotaxis of human T cells is regulated by a Gi- and phospholipase C-dependent pathway and not via activation of MEK/p44/p42 MAPK nor Akt/PI-3 kinase. Blood 2003;102:1959-65.

30 Castro F, Cardoso AP, Gonçalves RM, et al. Interferon-Gamma at the crossroads of tumor immune surveillance or evasion. Front Immunol 2018;9:847.

31 Joyce JA, Fearon DT. T cell exclusion, immune privilege, and the tumor microenvironment. Science 2015;348:74-80.

32 Martínez-Lostao L, Anel A, Pardo J. How do cytotoxic lymphocytes kill cancer cells? Clin Cancer Res 2015;21:5047-56.

33 Liu F, Hu X, Zimmerman M, et al. Tnf $\alpha$ cooperates with IFN- $\gamma$ to repress $\mathrm{Bcl}-\mathrm{xL}$ expression to sensitize metastatic colon carcinoma cells to TRAIL-mediated apoptosis. PLoS One 2011;6:e16241.
34 Mombaerts $P$, lacomini J, Johnson RS, et al. RAG-1-deficient mice have no mature B and T lymphocytes. Cell 1992;68:869-77.

35 Ribas A, Wolchok JD. Cancer immunotherapy using checkpoint blockade. Science 2018;359:1350-5.

36 Blank CU, Haanen JB, Ribas A, et al. Cancer immunology The "cancer immunogram". Science 2016;352:658-60.

37 Ahrends T, Spanjaard A, Pilzecker B, et al. CD4 ${ }^{+}$T Cell Help Confers a Cytotoxic T Cell Effector Program Including Coinhibitory Receptor Downregulation and Increased Tissue Invasiveness. Immunity 2017:47:848-61.

38 Chen DS, Mellman I. Oncology meets immunology: the cancerimmunity cycle. Immunity 2013;39:1-10.

39 Bonaventura P, Shekarian T, Alcazer V, et al. Cold tumors: a therapeutic challenge for immunotherapy. Front Immunol 2019;10:168

40 Zhan T, Rindtorff N, Betge J, et al. Crispr/Cas9 for cancer research and therapy. Semin Cancer Biol 2019;55:106-19.

41 Brunner-Weinzierl MC, Rudd CE. Ctla-4 and PD-1 control of T-cell motility and migration: implications for tumor immunotherapy. Front Immunol 2018;9:2737.

42 Bertrand F, Montfort A, Marcheteau E, et al. Tnfo blockade overcomes resistance to anti-PD-1 in experimental melanoma. Nat Commun 2017:8:2256.

43 Lin H, Wei S, Hurt EM, et al. Host expression of PD-L1 determines efficacy of PD-L1 pathway blockade-mediated tumor regression. $J$ Clin Invest 2018;128:805-15.

44 Jeanbart L, Ballester M, de Titta A, et al. Enhancing efficacy of anticancer vaccines by targeted delivery to tumor-draining lymph nodes. Cancer Immunol Res 2014;2:436-47.

45 Dangaj D, Bruand M, Grimm AJ, et al. Cooperation between constitutive and inducible chemokines enables T cell engraftment and immune attack in solid tumors. Cancer Cell 2019;35:e10:885-900. 